\title{
Exocytosis of serotonin from the neuronal soma is sustained by a serotonin and calcium-dependent feedback loop
}

\author{
Carolina Leon-Pinzon ${ }^{1}$, Montserrat G. Cercós ${ }^{2}$, Paula Noguez ${ }^{1}$, Citlali Trueta $^{2}$ and \\ Francisco F. De-Miguel ${ }^{1 *}$
}

1 Instituto de Fisiología Celular-Neurociencias, Universidad Nacional Autónoma de México, México D.F., México

${ }^{2}$ Departamento de Neurofisiología, Instituto Nacional de Psiquiatriìa Ramoin de la Fuente Munñiz, México D.F,, México

\section{Edited by:}

Dieter Wicher, Max Planck Institute for Chemical Ecology, Germany

\section{Reviewed by:}

Ulf Bickmeyer, Alfred Wegener Institute, Germany

Marco Canepari, INSERM, France

\section{*Correspondence:}

Francisco F. De-Miguel, Instituto de Fisiología Celular-Neurociencias, Universidad Nacional Autónoma de México, Circuito Exterior, Ciudad Universitaria, Apartado Postal 14-740. C.P. 04510, México D.F., México

e-mail: ffernand@ifc.unam.mx
The soma of many neurons releases large amounts of transmitter molecules through an exocytosis process that continues for hundreds of seconds after the end of the triggering stimulus. Transmitters released in this way modulate the activity of neurons, glia and blood vessels over vast volumes of the nervous system. Here we studied how somatic exocytosis is maintained for such long periods in the absence of electrical stimulation and transmembrane $\mathrm{Ca}^{2+}$ entry. Somatic exocytosis of serotonin from dense core vesicles could be triggered by a train of 10 action potentials at $20 \mathrm{~Hz}$ in Retzius neurons of the leech. However, the same number of action potentials produced at $1 \mathrm{~Hz}$ failed to evoke any exocytosis. The $20-\mathrm{Hz}$ train evoked exocytosis through a sequence of intracellular $\mathrm{Ca}^{2+}$ transients, with each transient having a different origin, timing and intracellular distribution. Upon electrical stimulation, transmembrane $\mathrm{Ca}^{2+}$ entry through L-type channels activated $\mathrm{Ca}^{2+}$-induced $\mathrm{Ca}^{2+}$ release. A resulting fast $\mathrm{Ca}^{2+}$ transient evoked an early exocytosis of serotonin from sparse vesicles resting close to the plasma membrane. This $\mathrm{Ca}^{2+}$ transient also triggered the transport of distant clusters of vesicles toward the plasma membrane. Upon exocytosis, the released serotonin activated autoreceptors coupled to phospholipase $\mathrm{C}$, which in turn produced an intracellular $\mathrm{Ca}^{2+}$ increase in the submembrane shell. This localized $\mathrm{Ca}^{2+}$ increase evoked new exocytosis as the vesicles in the clusters arrived gradually at the plasma membrane. In this way, the extracellular serotonin elevated the intracellular $\mathrm{Ca}^{2+}$ and this $\mathrm{Ca}^{2+}$ evoked more exocytosis. The resulting positive feedback loop maintained exocytosis for the following hundreds of seconds until the last vesicles in the clusters fused. Since somatic exocytosis displays similar kinetics in neurons releasing different types of transmitters, the data presented here contributes to understand the cellular basis of paracrine neurotransmission.

Keywords: exocytosis, extrasynaptic, somatic exocytosis, extrasynaptic release, serotonin, 5-HT, calcium, positive feedback

\section{INTRODUCTION}

In addition to the canonical release of transmitters from synapses, many neuron types release transmitters or peptides by exocytosis from their soma (For review see Trueta and De-Miguel, 2012). A brief train of impulses at high frequency or a long depolarization evoke a "large-scale" somatic exocytosis, in which large amounts of transmitter molecules are released for hundreds of seconds (Puopolo et al., 2001; Trueta et al., 2003; Soldo et al., 2004; Zhang et al., 2007; Kaushalya et al., 2008). This release seems to be responsible for the modulation of many functions in the nervous system (for review see Trueta and De-Miguel, 2012). Since somatic exocytosis depends on transmembrane $\mathrm{Ca}^{2+}$ entry (Sun and Poo, 1987; Chen et al., 1996; Jaffe et al., 1998; Puopolo et al., 2001; Trueta et al., 2003; Soldo et al., 2004; Huang et al., 2007; Kaushalya et al., 2008; Hirasawa et al., 2009), one wonders how it is maintained for such long periods after electrical stimulation and transmembrane $\mathrm{Ca}^{2+}$ entry have ended.

To study this problem we took advantage of the serotonergic Retzius neurons of the leech, in which most fine mechanisms of serotonin (5-HT) exocytosis from the synapses and soma were first elucidated (For review see Nicholls and Kuffler, 1990; DeMiguel and Trueta, 2005). The size of these neurons and the possibility to isolate them and keep them in culture provide excellent experimental conditions to understand cellular principles of 5-HT neurotransmission that have later been confirmed in other neuron types, including those of mammals (for review see Trueta and De-Miguel, 2012). The large soma $(60-80 \mu \mathrm{m}$ diameter) of Retzius neurons contains 5-HT packaged in 100nm diameter dense core vesicles (Coggeshall, 1972; Bruns et al., 2000). At rest, hundreds of these vesicles are tightly assembled 
in clusters that remain at a distance from the plasma membrane (De-Miguel et al., 2012; Trueta and De-Miguel, 2012). In response to a train of 10 action potentials at $20 \mathrm{~Hz}$, a microtubule-based transport mobilizes $80-110$ of these vesicle clusters to different spots of the plasma membrane (Trueta et al., 2004, 2012; De-Miguel et al., 2012) where all the vesicles in each cluster undergo exocytosis within the following 100-400s (De-Miguel et al., 2012). Other vesicle clusters may fuse later at the same plasma membrane spot in response to the same stimulation train (De-Miguel et al., 2012). We have estimated that a single $20-\mathrm{Hz}$ train evokes exocytosis from 60,000 to 100,000 vesicles/soma. By contrast, stimulation with 10 impulses delivered at $1 \mathrm{~Hz}$ fails to evoke this large-scale exocytosis, and in electron micrographs the vesicle clusters appear at their resting positions (Trueta et al., 2003; De-Miguel et al., 2012). Somatic exocytosis is abolished by blocking transmembrane $\mathrm{Ca}^{2+}$ entry through L-type $\mathrm{Ca}^{2+}$ channels (Trueta et al., 2003), or reduced by blocking $\mathrm{Ca}^{2+}$. induced $\mathrm{Ca}^{2+}$ release (Trueta et al., 2004). However, how $\mathrm{Ca}^{2+}$ entry evokes such delayed somatic exocytosis and how exocytosis is sustained yet need to be explored. The answer to these questions would provide the cellular basis to understand the wider phenomenon of the paracrine modulation of the nervous system.

In this study we dissected the steps from electrical stimulation until the end of the large-scale somatic exocytosis. Exocytosis was stimulated by a train of 10 action potentials at $20 \mathrm{~Hz}$ upon intracellular injection of current pulses. The kinetics of exocytosis from single vesicle clusters was accurately measured from the cumulative fluorescence of FM styryl dyes as vesicles fused with the plasma membrane and were retrieved just below the neuronal surface (Betz and Bewick, 1992). This was possible, since upon endocytosis the vesicle clusters remain in the submembrane shell for minutes before being recycled (Trueta et al., 2012). The amount of exocytosis was quantified as the number of FM1-43 fluorescent spots/soma (Betz and Bewick, 1992), which indicates the number of vesicle clusters that underwent exocytosis. The kinetics of the intracellular $\mathrm{Ca}^{2+}$ changes was measured from fluorescence increases of $\mathrm{Ca}^{2+}$-sensitive dyes injected intracellularly (Gee et al., 2000).

\section{MATERIALS AND METHODS ETHICS STATEMENT}

Animal research was conducted according to the statements of the Animal Committee of the Instituto de Fisiología Celular, UNAM, México.

\section{ISOLATION AND CULTURE OF NEURONS}

Imaging experiments were performed in cultured Retzius neurons of leeches Hirudo verbana (Siddall et al., 2007). Individual neurons were isolated by suction through a glass pipette (Dietzel et al., 1986). Neurons were then rinsed several times in L-15 culture medium (Sigma-Aldrich) supplemented with $6 \mathrm{mg} \mathrm{ml}^{-1}$ glucose, $0.1 \mathrm{mg} \mathrm{ml}^{-1}$ gentamicin and $2 \%$ heat- inactivated fetal bovine serum and then plated on glass-bottomed culture dishes precoated with concanavalin-A (Sigma-Aldrich). Experiments were performed at $18^{\circ} \mathrm{C}$ after $1-8$ days in culture.

\section{ELECTRICAL STIMULATION AND RECORDING}

Electrical stimulation consisted of trains of 10 action potentials produced by $10-\mathrm{ms}$ current pulses delivered at 1 or $20 \mathrm{~Hz}$ (Trueta et al., 2003; De-Miguel et al., 2012) through a borosilicate microelectrode with a resistance of 18-30 M $\Omega$ when filled with $2 \mathrm{M}$ potassium acetate (KAc). The amplitude of the current pulses was adjusted in every neuron between 5 and $8 \mathrm{nA}$, so that each pulse would produce one action potential. The neuronal resting potential was maintained at $-60 \mathrm{mV}$ by direct current injection. Electrical recordings were acquired by an intracellular amplifier AxoClamp 2B (Axon Instruments) connected to an analog-todigital board Digidata 1200 (Axon Instruments) that acquired at a sampling frequency of $20 \mathrm{KHz}$ using pCLAMP9 software (Axon Instruments). Data were stored in a PC.

To test for possible 5-HT activation of transmembrane currents, voltage clamp and transmembrane current recordings were made under discontinuous single-electrode voltage-clamp conditions. The quality of the clamp conditions was tested by continuously monitoring the time constant of the system at fast speed. The voltage was clamped at $-60 \mathrm{mV}$ and stimulation consisted of 10 voltage pulses of $10 \mathrm{~ms}$ to $+10 \mathrm{mV}$ at $20 \mathrm{~Hz}$. Action potentials during the $20-\mathrm{Hz}$ train could not be clamped. However, good voltage clamp conditions were obtained after the train and there were no significant current changes in the minutes following stimulation.

\section{MEASUREMENTS OF EXOCYTOSIS}

We measured the cumulative fluorescence increase of FM styryl dyes (Molecular Probes) produced by the progressive exo/endocytosis of dense core vesicles in the clusters (Betz and Bewick, 1992; De-Miguel et al., 2012). FM1-43 (Molecular Probes) was used for measuring only exocytosis and FM464 (Molecular Probes) was used in combination with Fluo-4 for simultaneous measurements of exocytosis and $\mathrm{Ca}^{2+}$. Both compounds were added to the bath at a final $2 \mu \mathrm{M}$ dilution and $10 \mathrm{~min}$ later neurons were impaled and hyperpolarized to $-60 \mathrm{mV}$ by DC current injection to avoid spontaneous firing. The values of exocytosis were measured as the number of FM1-43 spots/soma normalized to the 91 spots/soma produced in response to $20-\mathrm{Hz}$ stimulation. These data were obtained from previous experiments (Trueta et al., 2003, 2004). The reason for using our previous data was that due to their photo-damage equivalent spot-counting could not be made in the neurons that had been used for kinetic measurements. The counts in response to $20-\mathrm{Hz}$ stimulation were considered as $100 \%$, since at this frequency somatic exocytosis reaches its saturation levels (Trueta and De-Miguel, in preparation).

\section{MEASUREMENTS OF INTRACELLULAR $\mathrm{Ca}^{2+}$ INCREASES}

Relative changes in the intracellular $\mathrm{Ca}^{2+}$ concentration were measured with the $\mathrm{Ca}^{2+}$-sensitive fluorescent dyes Fluo-4 and Fluo-5F pentapotassium salt (Molecular probes). An advantage of these Fluo dyes is that both can be excited with a single wavelength and therefore allow a fast $(100 \mathrm{~ms} /$ image $)$ imaging rate and /or long acquisition periods when compared with ratiometric dyes, thus reducing bleaching and neuron damage. This was 
particularly critical for our experiments when imaging simultaneously $\mathrm{Ca}^{2+}$ and exocytosis, since two images were acquired for each time point over several minutes. To calibrate the $\mathrm{Ca}^{2+}$ concentrations we also tried Fura-2 imaging. However, the high sampling speed necessary to detect the fast $\mathrm{Ca}^{2+}$ transient required to double the imaging rates and neurons in these conditions were damaged rapidly by the Fura- 2 excitation and emission wavelengths. For this reason we sacrificed the concentration measurements to correlate the precise kinetics of the $\mathrm{Ca}^{2+}$ transients with those of exocytosis. Dyes had to be injected by iontophoresis since Retzius neurons do not retain esterase-coupled dyes. For this, the dyes were dissolved in water at a concentration of $5 \mathrm{mM}$ and were injected into the soma by a $4 \mathrm{nA}$ hyperpolarizing current for 4-6 min using borosilicate microelectrodes. The electrode tip was back-filled with the dye solution and the microelectrode was then filled with $0.1 \mathrm{M} \mathrm{KCl}$. Imaging was made 10-15 min after the dye had been loaded.

\section{PITFALLS AND CONSIDERATIONS IN THE USE OF $\mathrm{Ca}^{2+}$ SENSITIVE DYES}

Although we detected $\mathrm{Ca}^{2+}$ spikes in response to individual action potentials with both Fluo dyes, the low affinity $(2.5 \mu \mathrm{M})$ Fluo-5F could not detect the small $\mathrm{Ca}^{2+}$ transient described in the results sections. For this reason most of the experiments reported here were made by using the higher affinity $(\mathrm{Kd}=345 \mathrm{nM})$ Fluo4 , with which we consistently detected the small $\mathrm{Ca}^{2+}$ transient. A major concern of the use of high affinity dyes for our purposes is the possibility that dye saturation distorts the kinetics of the $\mathrm{Ca}^{2+}$ dynamics and exocytosis. However, that the kinetics of the fast $\mathrm{Ca}^{2+}$ transient obtained with either Fluo dye were identical suggested that Fluo-4 was not saturated under our experimental conditions. This was further tested by the addition of ionomycin $(5 \mu \mathrm{M})$ to neurons injected with high affinity dye after recording the transient evoked by $20 \mathrm{~Hz}$ stimulation. Ionomycin produced fluorescence increases to levels high above the peak fluorescence of the $\mathrm{Ca}^{2+}$ transients. In addition, neurons that became damaged during the experiments had similar fluorescence increases. These evidences indicate that the somatic $\mathrm{Ca}^{2+}$ increases in response to electrical stimulation were not produced under dye-saturation conditions.

We also assume that any distortion of the intracellular $\mathrm{Ca}^{2+}$ kinetics due to buffering by Fluo- 4 did not affect significantly our results, since such distortions occur within miliseconds (Sala and Hernández-Cruz, 1990; Neher and Augustine, 1992; Sabatini and Regehr, 1998) while the time courses of the $\mathrm{Ca}^{2+}$ transients we recorded ranged from hundreds of miliseconds to minutes. Moreover, the time courses of these distortions are usually faster than our imaging sampling speed. For all these reasons, the $\mathrm{Ca}^{2+}$ kinetics we report seem accurate descriptions of the intracellular $\mathrm{Ca}^{2+}$ dynamics. It is relevant also to mention here that the kinetics of exocytosis were similar with and without injection of $\mathrm{Ca}^{2+}$ sensitive dye. This indicates that Fluo- 4 is not producing significant changes in the $\mathrm{Ca}^{2+}$ or exocytosis dynamics. In this regard, somatic exocytosis in our experiments responded in the presence of high affinity dyes similarly to chromaffin cells loaded with Fura-2 (Augustine and Neher, 1992; Neher and Augustine, 1992; Chow et al., 1996; Klingauf and Neher, 1997), in which exocytosis also occurs from dense core vesicles and is slower than in synapses.

\section{FLUORESCENCE IMAGING}

For experiments using a single dye individual neurons were viewed at their soma equator with a Nikon Eclipse TE 200 inverted microscope through a Nikon 100X oil-immersion objective (NA 1.40). Fluorescence measurements of FM1-43 or Fluo-4 were performed with excitation and emission wavelengths at 488 and $535 \mathrm{~nm}$ respectively. A cooled CCD camera (IMAGO, Till Vision) acquired image sequences of $640 \times 480$ pixels. To study fast Fluo-4 fluorescence transients in response to the stimulation trains, images were acquired every $100 \mathrm{~ms}$ for $60 \mathrm{~s}$. To follow FM styryl dye changes or the long-lasting Fluo-4 transients, separate images were acquired every $2 \mathrm{~s}$ for $15 \mathrm{~min}$. The image sequences were stored digitally by using TILLvisION software.

For simultaneous recordings of exocytosis and $\mathrm{Ca}^{2+}$ signals, confocal imaging of FM4-64 and Fluo-4 fluorescence was carried out using an Olympus Fluoview FV1000 upright confocal scanning microscope using $473 \mathrm{~nm}$ for Fluo-4 excitation and $560 \mathrm{~nm}$ for FM4-64 excitation. For the simultaneous imaging fluorescence was acquired with a $60 \mathrm{X}$ water immersion objective (1.1 NA). Fluorescence was detected in parallel by a spectral-based detector capturing 503-543 nm for the Fluo-4 emission and 600-700 nm for the FM4-64 emission. Time-lapse sequences were made by acquiring an image every $2 \mathrm{~s}$ for $20 \mathrm{~min}$. Images were stored digitally by using Fluoview 3.1 software (Olympus).

\section{IMAGE ANALYSIS}

We used Image-J software (National Institutes of Health) for most of the analysis. The time series of images were aligned with the StackReg plug-in. The mean fluorescence intensity was measured along time or space sequences from 1.8 to $2 \mu \mathrm{m}^{2}$ regions of interest (ROIs) that contained a fluorescent spot. These areas were chosen because they correspond to the average area of a vesicle cluster (Trueta et al., 2003; De-Miguel et al., 2012). To calculate the fluorescence changes relative to the resting fluorescence, the average intensity in the 20 frames before stimulation $\left(\mathrm{F}_{0}\right)$ was subtracted from the intensity of that ROI at each time $[\mathrm{F}(\mathrm{t})]$. The difference was divided by $F_{0}$, to generate $\Delta F / F_{0}$. For simplicity, throughout the text and figures this normalization is referred to as dF/F. Surface plots were made by using an RGB 8 bit color scale calibrated in the dynamic interval. Plotting and curve fitting were performed using Igor Pro 6.2 software (Wavemetrics). Data are presented as mean \pm s.e.m. Statistical comparisons were performed using unpaired two tailed Student's $t$-test.

\section{PHARMACOLOGY}

To block L-type $\mathrm{Ca}^{2+}$ channels we used nimodipine $(10 \mu \mathrm{M}$; Sigma-Aldrich); to eliminate $\mathrm{Ca}^{2+}$-induced $\mathrm{Ca}^{2+}$ release we used a combination of ryanodine $(100 \mu \mathrm{M}$, Invitrogen) and thapsigargin (1.6 $\mu \mathrm{M}$; Invitrogen). 5-HT receptors were blocked with methysergide ( $140 \mu \mathrm{M}$; Sigma-Aldrich) and to block PLC neurons were preincubated for 30 min with U-73122 (10 $\mu \mathrm{M}$; SigmaAldrich). All drugs were applied to the bathing fluid from 500X stock solutions $15 \mathrm{~min}$ before images were taken, except for $\mathrm{U}$ 73122, which was added $30 \mathrm{~min}$ before. 


\section{ELECTRON MICROSCOPY}

The general procedures were as in Trueta et al. (2012). In brief, neurons in isolated segmental ganglia were stimulated with 10 trains of 10 impulses at a frequency of $1 \mathrm{~Hz}$ delivered at $1 \mathrm{~min}$ intervals. Ganglia were then perfused with $0.08 \mathrm{M}$ cacodylate buffer ( $\mathrm{pH} 7.4$; Sigma-Aldrich) and fixed for $60 \mathrm{~min}$ with $0.6 \%$ glutaraldehyde and $0.4 \%$ paraformaldehyde, followed by postfixation for $60 \mathrm{~min}$ in $1.0 \%$ osmium tetroxide (Kuffler et al., 1987). Thin (70-100 nm) sections were observed in a JEOL 1010 electron microscope (JEOL USA Inc.). Electron micrographs were digitized at $1200 \mathrm{dpi}$ in CMYK mode. For illustration purposes endoplasmic reticulum (ER) was pseudo-colored by using the fast selection and the color equilibrium tools of Photoshop (Adobe).

\section{RESULTS}

\section{KINETICS OF SOMATIC EXOCYTOSIS AND INTRACELLULAR $\mathrm{Ca}^{2+}$}

Electrical stimulation of individual neurons with a $20-\mathrm{Hz}$ train (Figure 1A, left) lasting $0.5 \mathrm{~s}$ produced somatic exocytosis for up to $400 \mathrm{~s}$, as seen by the kinetics of the formation of fluorescent FM1-43 spots in the soma periphery (Figure 1B). Each spot was formed by the integrated fluorescence upon exocytosis from the vesicles in one cluster (De-Miguel et al., 2012). The fluorescence kinetics of $61 \%$ of the spots studied in 19 neurons had a sigmoidal shape (Figure 1C, light red traces). The rest of the spots displayed two and occasionally three sigmoidal fluorescence increases (Figure 1C, dark red), each of which was due to the fusion of a subsequent vesicle cluster. We have previously shown (De-Miguel et al., 2012) that the sigmoidal shape of the fluorescence kinetics has the following components: its latency is determined by the resting distance from the vesicle clusters to the plasma membrane and by the transport velocity of the vesicle cluster; the slope of the fluorescence increase expresses the rate of exocytosis; the plateau is reached upon the end of exocytosis, and the maximum fluorescence level is proportional to the cumulative number of vesicles that fused. As expected from our previous experience, stimulation with a $1-\mathrm{Hz}$ train failed to produce a significant formation of FM1-43 fluorescence spots (Figure 1C, gray traces). Consistently, electron micrographs of neurons stimulated at this frequency showed the vesicle clusters at their resting positions (Supplementary Figure 1).

To explore how $\mathrm{Ca}^{2+}$ contributes to this large-scale somatic exocytosis, the kinetics of exocytosis and intracellular $\mathrm{Ca}^{2+}$ were measured simultaneously by imaging the fluorescence of FM464 and Fluo-4 dyes. A major concern of these measurements is that high affinity $\mathrm{Ca}^{2+}$ sensitive dyes may affect the intracellular free $\mathrm{Ca}^{2+}$ concentration and therefore exocytosis. However, as shown in Figure 1D, the kinetics of exocytosis in neurons injected with Fluo-4 was similar to that obtained from neurons imaged in its absence. The methods section contains an account of the precautions taken for the use of $\mathrm{Ca}^{2+}$ sensitive dyes to measure $\mathrm{Ca}^{2+}$ dynamics and exocytosis simultaneously. Moreover, as will be seen below, there was also good correlation between the kinetics of exocytosis and intracellular $\mathrm{Ca}^{2+}$ in pharmacological experiments.

Simultaneous confocal imaging of FM4-64 and Fluo-4 fluorescence from membrane areas that exhibited exocytosis in response to a $20-\mathrm{Hz}$ train showed a complex relationship between exocytosis and $\mathrm{Ca}^{2+}$ (Figure 1E). A $20-\mathrm{Hz}$ train produced a sequence of three $\mathrm{Ca}^{2+}$ transients, each of which could be unmistakably identified by its kinetics, its characteristic localization and its effect on exocytosis. The first $\mathrm{Ca}^{2+}$ transient was a fast spike coupled to the stimulation train (thus we will refer to it as fast $\mathrm{Ca}^{2+}$ transient; 1 in Figure 1E). This fast $\mathrm{Ca}^{2+}$ transient invaded rapidly the whole somatic cytoplasm (see Movie 1). The second $\mathrm{Ca}^{2+}$ transient was small and purely submembrane (we will refer to it as small $\mathrm{Ca}^{2+}$ transient). This small $\mathrm{Ca}^{2+}$ transient appeared between the peak of the large $\mathrm{Ca}^{2+}$ transient and the large-scale exocytosis ( 2 in Figure 1E). The third $\mathrm{Ca}^{2+}$ transient was large in amplitude and duration (therefore, we will refer to it as large $\mathrm{Ca}^{2+}$ transient). The large transient was also restricted to the submembrane shell (3 in Figure 1E), grew during the dynamic range of exocytosis and started to decay when exocytosis was near end. The small and the large $\mathrm{Ca}^{2+}$ transients were absent upon $1-\mathrm{Hz}$ stimulation (Figure 1E, gray trace).

\section{FREQUENCY-DEPENDENCE OF THE FAST $\mathrm{Ca}^{2+}$ TRANSIENT}

Although the fast $\mathrm{Ca}^{2+}$ transient ended before the onset of the large-scale exocytosis, the evidence presented before suggested that it coupled electrical stimulation with exocytosis. To understand this paradox we compared its characteristics with to those of the $\mathrm{Ca}^{2+}$ transient in response to a $1-\mathrm{Hz}$ train, which does not evoke exocytosis (Figure 2). The fast $\mathrm{Ca}^{2+}$ transient upon $20-\mathrm{Hz}$ stimulation started to develop right after the first impulse and peaked $600 \mathrm{~ms}$ later (Figures 2B,D, Movie 1), that is $\sim 100 \mathrm{~ms}$ after the last impulse (note that these values are approximations due to our 100-ms imaging interval). The peak amplitude of the fast $\mathrm{Ca}^{2+}$ transient recorded by Fluo- 4 in the submembrane shell was $804 \pm 52 \%$ of the baseline fluorescence value and its decay was exponential $\left(R^{2}>0.90\right)$ with a time constant of $2.0 \pm 0.2 \mathrm{~s}$ ( $n=6$ cells; Figure 2D). This kinetics was identical when recorded with Fluo-5F or Fluo-4, thus indicating that Fluo4 did not saturate in these experimental conditions (Figure 2D). However, a major difference was that the fluorescence levels detected by Fluo-5F always returned to baseline levels without unveiling the small $\mathrm{Ca}^{2+}$ transient detected by Fluo-4 during the decay of the fast $\mathrm{Ca}^{2+}$ transient (Figure 2D, arrowhead). The fast $\mathrm{Ca}^{2+}$ transient arrived rapidly at the soma central region $(25 \mu \mathrm{m}$ away from the plasma membrane) in every neuron tested, where it also peaked by $600 \mathrm{~ms}$ (Figures 2B,D). However, at the center its peak amplitude was $54 \%$ of that in the submembrane shell. From then fluorescence returned exponentially to baseline levels (Figure 2D).

The $\mathrm{Ca}^{2+}$ transient produced by a $1-\mathrm{Hz}$ train was different (Figures 2C,D; see Movie 2). In the submembrane shell of the soma this transient was a succession of 10 small $\mathrm{Ca}^{2+}$ spikes, with each coupled to an impulse of the train. The peaks of the individual spikes had a $\sim 100 \mathrm{~ms}$ rise time $(n=6)$, again with the resolution limited by our $100 \mathrm{~ms} /$ image sampling rate. The temporal summation of the subsequent $\mathrm{Ca}^{2+}$ spikes produced that the maximal Fluo-4 fluorescence value $(263 \pm 15 \%$ of the baseline value) was reached after the last impulse of the train. The maximum fluorescence amplitude was only $33 \%$ of that of the fast $\mathrm{Ca}^{2+}$ transient upon $20-\mathrm{Hz}$ stimulation. After the last spike of the $1 \mathrm{~Hz}$ train, fluorescence decayed exponentially with a time 


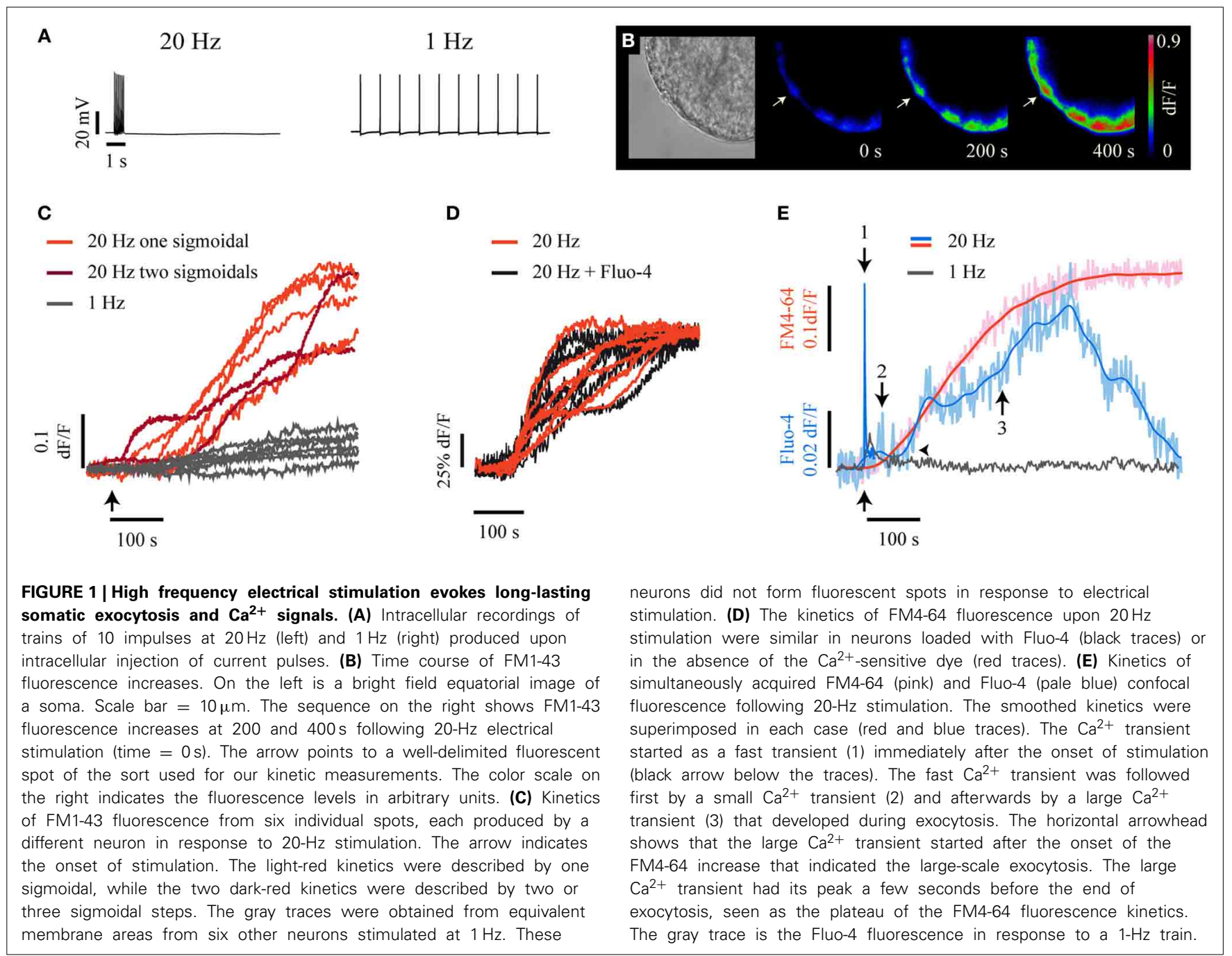

constant of $1.7 \pm 0.3 \mathrm{~s}$. This decay time was similar $(\mathrm{p}=0.32)$ to that of the fast $\mathrm{Ca}^{2+}$ transient upon $20-\mathrm{Hz}$ stimulation. At the soma center the maximal amplitude of the transient evoked by $1-\mathrm{Hz}$ stimulation was $72 \%$ of that in the periphery.

That the amplitude of the $\mathrm{Ca}^{2+}$ transient evoked by 20 $\mathrm{Hz}$ stimulation was $67 \%$ larger than that obtained at $1-\mathrm{Hz}$ (Figure 2E) suggested that it is the peak amplitude of the $\mathrm{Ca}^{2+}$ transient (which indicates the maximum $\mathrm{Ca}^{2+}$ concentration reached) what triggers exocytosis. Moreover, the amplitude of the transient evoked by $20-\mathrm{Hz}$ stimulation was $38.5 \%$ larger than the sum of the peak amplitudes of the $10 \mathrm{Ca}^{2+}$ spikes evoked by a $1-\mathrm{Hz}$ train. Since transmembrane $\mathrm{Ca}^{2+}$ entry upon subsequent voltage steps does not facilitate in the soma of these neurons (Stewart et al., 1989), the supra-linear amplitude increase of the transient evoked at $20-\mathrm{Hz}$ suggests that extracellular $\mathrm{Ca}^{2+}$ entry evokes intracellular $\mathrm{Ca}^{2+}$ release. Note that the transients produced by either stimulation frequency had the same decay time, thus indicating that the $\mathrm{Ca}^{2+}$ buffering in response to both stimulation frequencies was similar and operated within its dynamic range. In these conditions, the integral values of the transients over time provide a measure of the amount of the free $\mathrm{Ca}^{2+}$ during the transients regardless on the $\mathrm{Ca}^{2+}$ origin and kinetics. As seen in Figure 2F, the integral value of the transients evoked by $20-\mathrm{Hz}$ stimulation was $27 \%$ larger than that evoked by $1-$ $\mathrm{Hz}$ stimulation. That the amplitude differences were much larger than the integral differences supports that it is the maximum $\mathrm{Ca}^{2+}$ concentration reached and not the amount of free $\mathrm{Ca}^{2+}$ what activates exocytosis. This data also supports the idea that $\mathrm{Ca}^{2+}$ entry upon $20 \mathrm{~Hz}$ stimulation evokes $\mathrm{Ca}^{2+}$-induced $\mathrm{Ca}^{2+}$ release.

\section{COMPONENTS OF THE FAST $\mathrm{Ca}^{2+}$ TRANSIENT AND THEIR CONTRIBUTION TO EXOCYTOSIS}

The pharmacological dissection of the components of the fast $\mathrm{Ca}^{2+}$ transient allowed us to understand its generation and spread, and provided us with tools to analyze how it evokes exocytosis. The fast $\mathrm{Ca}^{2+}$ transient had three components. The main component was a voltage-dependent $\mathrm{L}$ current, which was reduced by $75.1 \pm 7.3 \%$ by the L-type $\mathrm{Ca}^{2+}$ channel blocker nimodipine $(10 \mu \mathrm{M}$; Figures 3A,C). The same concentration of nimodipine produced a $75 \%$ reduction in the amount of somatic exocytosis, measured as the number of FM1-43 spots/soma in 


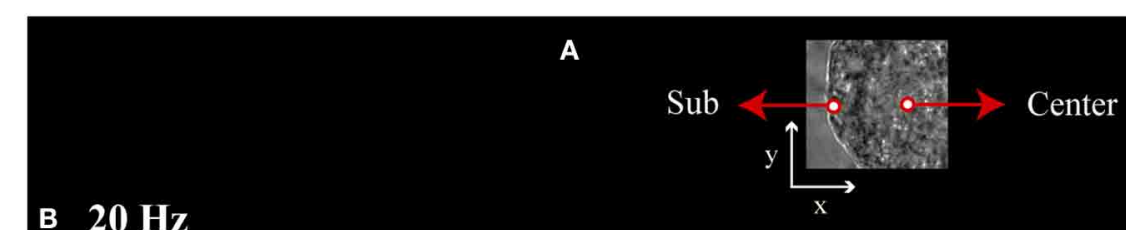

B $20 \mathrm{~Hz}$

$0 \mathrm{~s}$

$0.3 \mathrm{~s}$

$0.6 \mathrm{~s}$

$1.6 \mathrm{~s}$

$4.1 \mathrm{~s}$

$4.9 \mathrm{~s}$

$9.1 \mathrm{~s}$

$16.5 \mathrm{~s}$
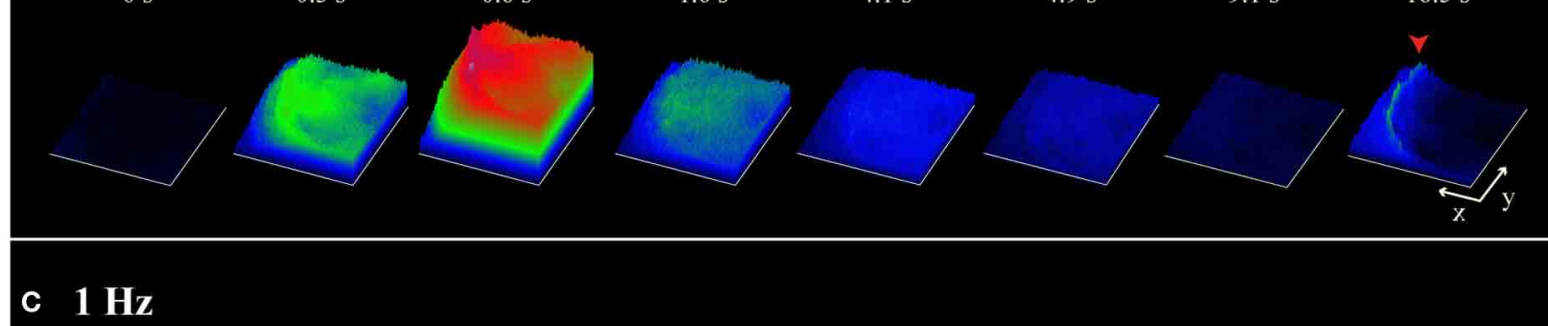

$0 \mathrm{~s}$

$0.3 \mathrm{~s}$

$0.6 \mathrm{~s}$

$1.6 \mathrm{~s}$

$4.1 \mathrm{~s}$

$4.9 \mathrm{~s}$

$9.1 \mathrm{~s}$

$16.5 \mathrm{~s}$

0
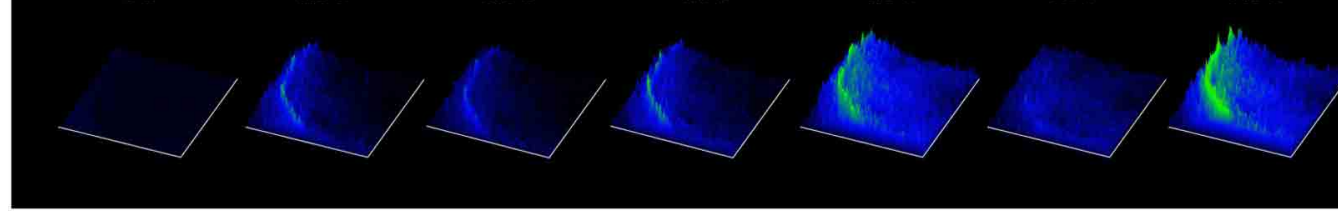

1

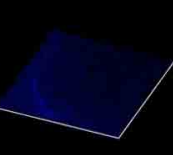

D

Submembrane

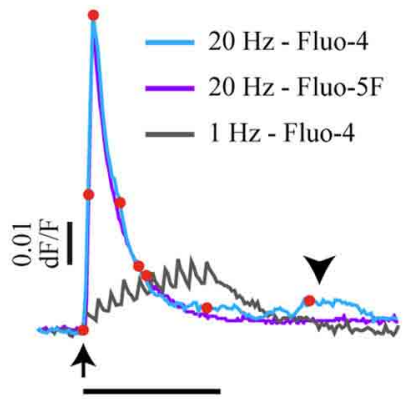

$10 \mathrm{~s}$

FIGURE 2 | Frequency-dependence of the fast $\mathrm{Ca}^{2+}$ transient. (A)

Bright field image of the soma from which the fluorescence surface plots in $\mathbf{( B , C )}$ were made. The $x$ and $y$ axis $=20 \mu \mathrm{m}$. (B) Sequence of Fluo-4 fluorescence surface plots obtained after $20-\mathrm{Hz}$ stimulation at $t=0 \mathrm{~s}$. The time is the same for $(\mathbf{B}, \mathbf{C})$ and corresponds to the time indicated by the red dots over the fast $\mathrm{Ca}^{2+}$ transient upon $20 \mathrm{~Hz}$ stimulation shown in (D). The $z$ axis is the fluorescence intensity in arbitrary units, according to the calibration on the right. At $0.6 \mathrm{~s}$ the fast $\mathrm{Ca}^{2+}$ transient had reached the soma center. A submembrane small $\mathrm{Ca}^{2+}$ transient appeared $16.5 \mathrm{~s}$ after the stimulation train (red arrowhead). See also the

supplemental Movie 1. (C) Sequence of Fluo-4 fluorescence surface plots upon $1-\mathrm{Hz}$ stimulation. This $\mathrm{Ca}^{2+}$ increases failed to invade the soma center. See also the supplemental Movie 2. (D) Superimposition of Fluo-4 and Fluo-5F fluorescence transients upon $20-\mathrm{Hz}$ stimulation (blue
$\mathbf{E}$

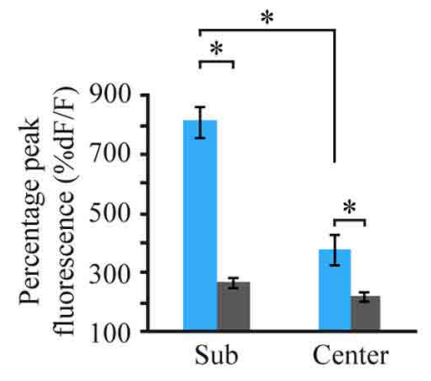

$\mathbf{F}$

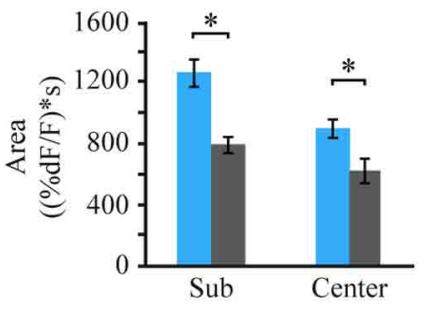

a different cell group (Trueta et al., 2003, see methods; $n=10$; Figure 3D). This indicated that $\mathrm{Ca}^{2+}$ entry through $\mathrm{L}$ channels was the predominant source to trigger exocytosis. The $25 \%$ residual of the fast $\mathrm{Ca}^{2+}$ transient was insensitive to nimodipine at doses up to $80 \mu \mathrm{M}$, although was completely abolished when cadmium $(200 \mu \mathrm{M})$ substituted $\mathrm{Ca}^{2+}$ in the external solution (not shown) to block transmembrane $\mathrm{Ca}^{2+}$ entry (Fernandez-DeMiguel et al., 1992). This experiment unveiled a second and yet unidentified transmembrane $\mathrm{Ca}^{2+}$ source. However, this remnant and purple respectively). The arrow pointing up indicates the onset of stimulation. The fluorescence kinetics with both dyes were identical, indicating that Fluo-4 was not saturated. Note also that the small $\mathrm{Ca}^{2+}$ transients (arrowhead) were not detected by the low affinity Fluo-5F. A transient in response to $1-\mathrm{Hz}$ (gray) stimulation in the submembrane (left) and central (right) regions was composed by 10 subsequent spikes, each synchronized to an action potential of the train. The transients produced by either stimulation frequency arrived attenuated at the soma center. (E) Normalized peak amplitude of the $\mathrm{Ca}^{2+}$ transients in response to $20-\mathrm{Hz}$ (blue) and $1-\mathrm{Hz}$ (gray) trains in the submembrane (Sub) and center areas of the soma (Center). The asterisks indicate significant differences $(p<0.05)$. (F) Integral values of the $\mathrm{Ca}^{2+}$ signals at either frequency in the submembrane and center areas. The larger integral of the transient upon $20-\mathrm{Hz}$ stimulation indicates a supra-linear intracellular $\mathrm{Ca}^{2+}$ increase.

$\mathrm{Ca}^{2+}$ transient was unable to evoke exocytosis, since the $25 \%$ of fluorescent spots/soma counted in these conditions was in the range of the values counted after $1-\mathrm{Hz}$ stimulation $(20 \pm 5 \%$; $n=6$ ), or after $20-\mathrm{Hz}$ stimulation when $\mathrm{Ca}^{2+}$ had been replaced by magnesium in the external solution to prevent transmembrane $\mathrm{Ca}^{2+}$ entry $(34 \pm 8 \% ; n=7$; Figure 3D). Moreover, a $21 \%$ of spots/soma was produced in the absence of stimulation $(n=6)$.

As predicted before, the third $\mathrm{Ca}^{2+}$ source contributing to the fast transient was $\mathrm{Ca}^{2+}$-induced $\mathrm{Ca}^{2+}$ release. Incubation 


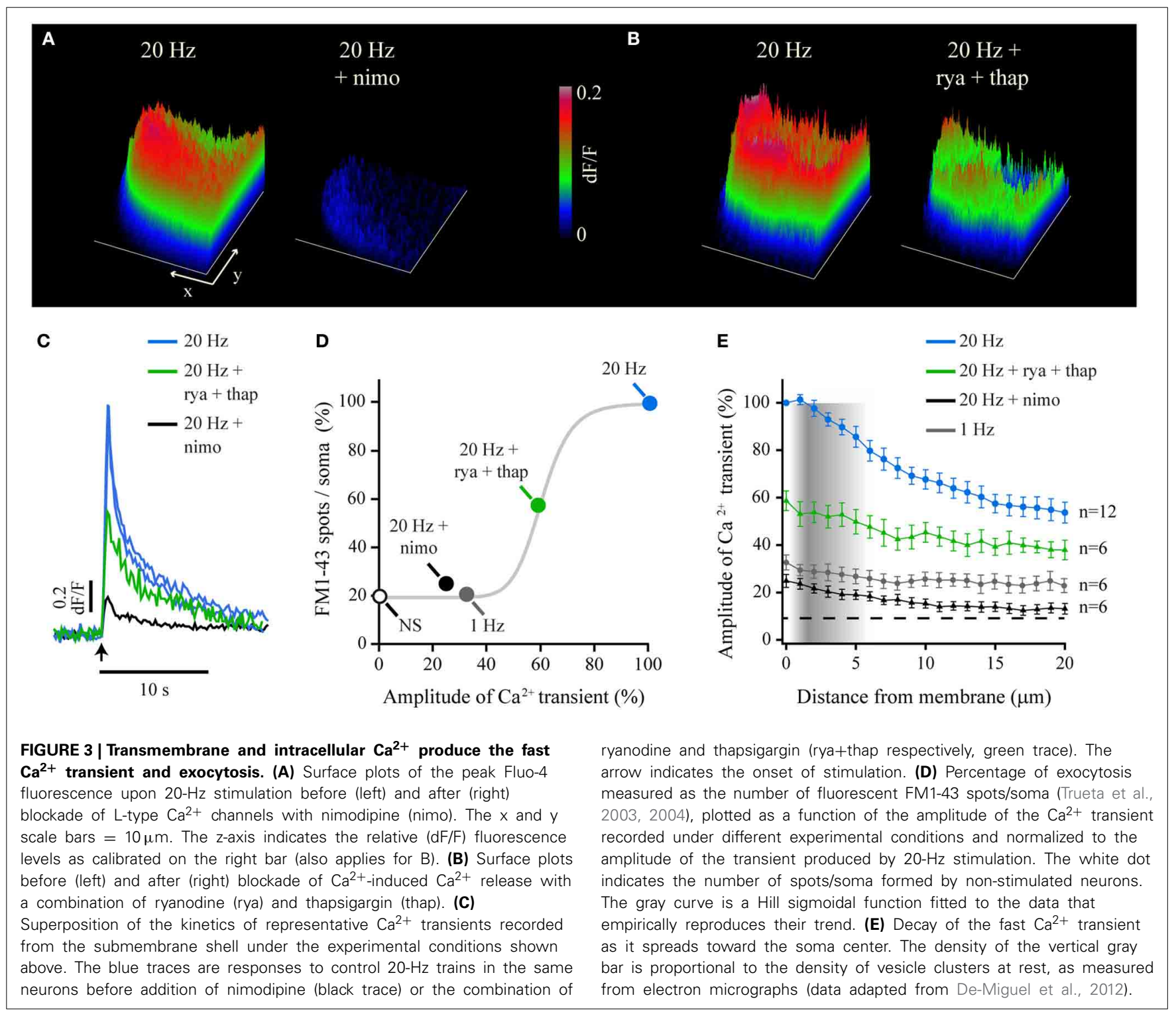

of six neurons with $100 \mu \mathrm{M}$ ryanodine and $1.6 \mu \mathrm{M}$ thapsigargin reduced the amplitude of the fast $\mathrm{Ca}^{2+}$ transient by 41 $\pm 5.1 \%$ (Figures 3B,C). $\mathrm{Ca}^{2+}$-induced $\mathrm{Ca}^{2+}$ release also contributed to exocytosis since pre-incubation of 11 neurons with $100 \mu \mathrm{m}$ ryanodine (Figure 3D) in our previous experiments (Trueta et al., 2004) reduced the number of FM1-43 spots/soma by $42 \%$. Figure 3D shows the percentage of fluorescent FM143 spots/soma plotted vs. the percentage peak amplitude of the fast $\mathrm{Ca}^{2+}$ transient obtained in each experimental condition. The $100 \%$ values were those obtained upon $20-\mathrm{Hz}$ stimulation (see Methods). The gray sigmoidal function in Figure 3D shows the trend of the data for illustration purposes. This function was fitted to the data owing to its similarities to the plot describing how the amount of exocytosis depends on the stimulation frequency (Trueta and De-Miguel, in preparation). These data confirm on one hand that the amount of exocytosis is determined by the amplitude of the fast $\mathrm{Ca}^{2+}$ transient. On the other hand data show that different $\mathrm{Ca}^{2+}$ sources cooperate to determine the number of vesicle clusters arriving at the plasma membrane.

A further explanation to how the fast $\mathrm{Ca}^{2+}$ transient determines the amount of vesicle clusters undergoing exocytosis came from how far the fast $\mathrm{Ca}^{2+}$ transient penetrates the cytoplasm. This is shown by plotting the average amplitude of the fast $\mathrm{Ca}^{2+}$ transients in different experimental conditions over the radial intracellular distance from the plasma membrane (Figure 3E). The plot is superimposed to the intracellular density of vesicle clusters at rest, as estimated from electron micrographs (DeMiguel et al., 2012). It may be seen that the amplitude of the fast $\mathrm{Ca}^{2+}$ transient decayed within the distance range in which the vesicle clusters accumulate at rest. Therefore, peripheral clusters receive a higher $\mathrm{Ca}^{2+}$ concentration than internal clusters. Since vesicle clusters establish tight bounds with mitochondria (DeMiguel et al., 2012), an attractive possibility is that the amount of vesicle clusters transported toward the plasma membrane 
depends on amplitude of the fast $\mathrm{Ca}^{2+}$ transient through the activation of mitochondrial ATP synthesis. By sensing a larger $\mathrm{Ca}^{2+}$ concentration the more peripheral clusters would receive more ATP for their transport.

\section{THE SMALL AND THE LARGE SUBMEMBRANE $\mathrm{Ca}^{2+}$ TRANSIENTS SUSTAIN EXOCYTOSIS}

Since the large-scale exocytosis starts after the end of the fast $\mathrm{Ca}^{2+}$ transient, we investigated the possibility that exocytosis is sustained by the small and the large $\mathrm{Ca}^{2+}$ transients. As mentioned before and shown in Figure 4A, both $\mathrm{Ca}^{2+}$ transients were purely submembrane in the seven neurons studied (see also Movie 1). Figure 4B shows the kinetics of simultaneously acquired Fluo4 and FM4-64 fluorescence. The two sigmoidal increases in the FM4-64 fluorescence correlate with the development of two $\mathrm{Ca}^{2+}$ transients. However, they were not produced by a transmembrane $\mathrm{Ca}^{2+}$ flow, since our voltage clamp records during exocytosis lacked any transmembrane currents (Figure 4C).

The small $\mathrm{Ca}^{2+}$ transient could be detected 6.6-24.0 s after the onset of the train (Figure 2D, arrowhead). By contrast, the large $\mathrm{Ca}^{2+}$ transient (Figures 4A,B) was only detected $14-35 \mathrm{~s}$ after the onset of the large-scale exocytosis (determined as the threshold for the FM4-64 fluorescence increase) in five out of seven neurons; that is $21-72 \mathrm{~s}$ after the onset of the stimulation train (Figure 4D). In two other neurons in which the onset of exocytosis had a longer latency (>68 s), the large $\mathrm{Ca}^{2+}$ transient anticipated exocytosis. However, in every neuron tested the large $\mathrm{Ca}^{2+}$ transient grew during the dynamic range of exocytosis to reach peak fluorescence levels 638-992\% above the baseline. The decay of the transient started $8 \mathrm{~s}$ before the end of exocytosis, when its rate had started to decline (Figures 4B,E). This value was calculated from the $y$-intercept of the line that fitted the time to peak of the large $\mathrm{Ca}^{2+}$ transient vs. the duration of exocytosis (Figure 4E). The small and the large submembrane $\mathrm{Ca}^{2+}$ transients were smaller and had a slower time course in submembrane segments that failed to develop FM4-64 fluorescent spots, thus suggesting that the intracellular $\mathrm{Ca}^{2+}$ had diffused from active exocytosis sites. These observations suggested that both submembrane $\mathrm{Ca}^{2+}$ transients received an input from exocytosis.

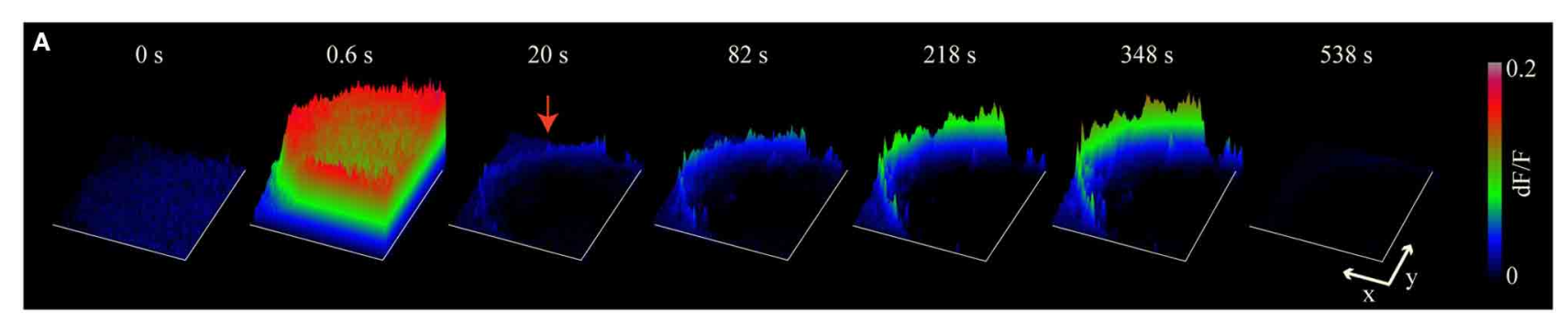

B

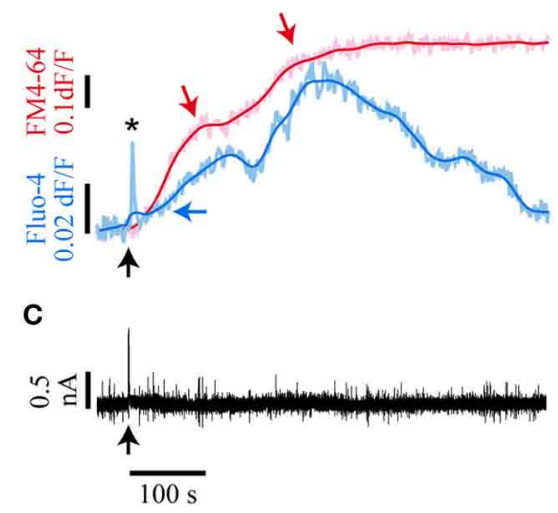

D

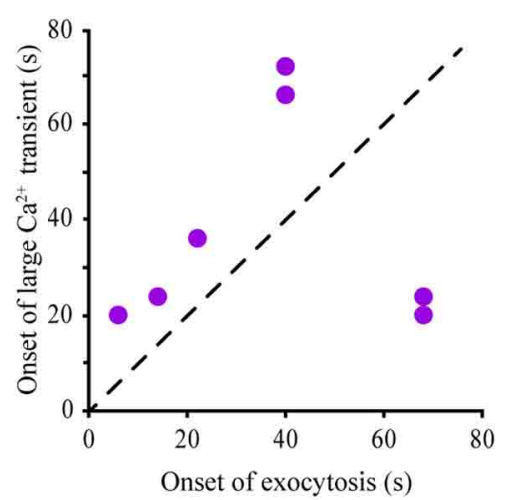

E

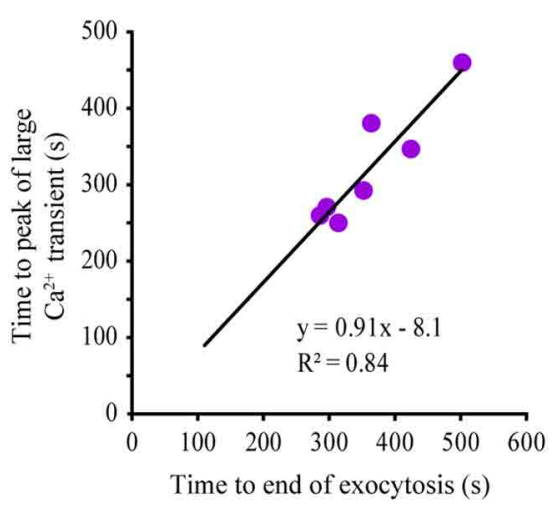

FIGURE 4 | Kinetics of the large $\mathrm{Ca}^{2+}$ transient and exocytosis.

(A) Sequence of surface plots of the Fluo-4 fluorescence in response to a $20-\mathrm{Hz}$ train. The onset of the train was at $t=0$. The frame at $0.6 \mathrm{~s}$ shows the peak of the fast $\mathrm{Ca}^{2+}$ transient; the frame at $20 \mathrm{~s}$ shows the small $\mathrm{Ca}^{2+}$ transient, and the subsequent frames show the development of the large $\mathrm{Ca}^{2+}$ transient. Note that the fluorescence increases were limited to the submembrane region of the soma. The $x$ and $y$ scale bars $=10 \mu \mathrm{m}$. The $z$-axis indicates the relative $(\mathrm{dF} / \mathrm{F})$ fluorescence levels as calibrated on the right bar. (B) Kinetics of simultaneously acquired FM4-64 (pink) and Fluo-4 (pale blue) confocal fluorescence following $20-\mathrm{Hz}$ stimulation. The black arrow indicates the onset of the $20-\mathrm{Hz}$ train. The kinetics of exocytosis had two sigmoidal components, each pointed by a red arrow. The smoothed kinetics (red and blue) are superimposed to each trace. The amplitude of the fast $\mathrm{Ca}^{2+}$ transient (asterisk) is truncated due to the $0.5-\mathrm{Hz}$ imaging acquisition frequency. The Fluo-4 large transient started to rise after the onset of the FM4-64 increase (horizontal blue arrow) and developed two peaks, each of which matched with each plateau of the FM4-64 fluorescence kinetics. (C) The transmembrane current during the large $\mathrm{Ca}^{2+}$ transient remained constant after $20-\mathrm{Hz}$ stimulation, thus eliminating the possibility that the large $\mathrm{Ca}^{2+}$ transient was produced by transmembrane $\mathrm{Ca}^{2+}$ entry. The arrow indicates the onset of the $20-\mathrm{Hz}$ train. (D) The large $\mathrm{Ca}^{2+}$ transient appeared after the onset of the large-scale exocytosis, as seen by the points above the dashed identity bar. This relationship was inverted in two neurons with long exocytosis latencies ( $70 \mathrm{~s})$. (E) The peak of the large $\mathrm{Ca}^{2+}$ transient was reached $8 \mathrm{~s}$ before the end of exocytosis, as shown by the negative $y$-intercept of the linear relationship in the plot. The parameters of the fit are shown in the plot. 


\section{5-HT RELEASE AND PHOSPHOLIPASE C ACTIVATION PRODUCED THE SUBMEMBRANE CA ${ }^{2+}$ TRANSIENTS AND EXOCYTOSIS}

To explore if the small and the large submembrane $\mathrm{Ca}^{2+}$ transients were produced by 5 -HT released upon exocytosis, neurons were stimulated with a $20-\mathrm{Hz}$ train in the presence of methysergide $(140 \mu \mathrm{M})$, an unspecific blocker of metabotropic 5-HT inverterbrate receptors. Methysergide abolished both submembrane $\mathrm{Ca}^{2+}$ transients without affecting the fast $\mathrm{Ca}^{2+}$ transient in the six neurons stimulated at $20 \mathrm{~Hz}$ (Figure 5A). In six other stimulated neurons methysergide abolished exocytosis (Figure 5B). These results indicated that 5-HT exocytosis activates autoreceptors, which then produce the submembrane $\mathrm{Ca}^{2+}$ transients that evoke more exocytosis. Consistently, iontophoretic applications of 5-HT to the soma surface produced a Fluo- 4 fluorescence increase in the submembrane area adjacent to the iontophoretic pipette (Supplementary Figure 2). By contrast, a bath perfusion with $1 \mu \mathrm{M} 5-\mathrm{HT}$, a concentration that in our hands produces several physiological effects without evoking action potentials in Retzius neurons (Sarkar et al., 2014), failed to evoke any exocytosis ( $\mathrm{n}=6$ neurons). These results suggest that the 5-HT-evoked submembrane $\mathrm{Ca}^{2+}$ transients sustain the large-scale somatic exocytosis, but the fast $\mathrm{Ca}^{2+}$ transient is required as a trigger.

We next investigated the mechanism by which the released 5-HT activates the small and the large submembrane $\mathrm{Ca}^{2+}$ transients. Although other experiments made in these neurons have shown brief transmembrane currents in response to 5-HT pulses (Lessmann and Dietzel, 1991; Beck et al., 2002), the lack of transmembrane currents in our records during the large scale 5-HT exocytosis (Figure 4C) suggested that both submembrane $\mathrm{Ca}^{2+}$ transients were produced by intracellular $\mathrm{Ca}^{2+}$ release. Extrasynaptic $5-\mathrm{HT}_{2}$ receptors in Retzius neurons are coupled to phospholipase C (PLC) (Drapeau et al., 1989; Sanchez-Armass et al., 1991), which produces inositol 1,4,5-triphosphate ( $\left.\mathrm{IP}_{3}\right)$ and intracellular $\mathrm{Ca}^{2+}$ release (Pozzan et al., 1994; Pandey et al., 1995; Barnes and Sharp, 1999). This pathway was then explored as the possible origin of the submembrane $\mathrm{Ca}^{2+}$ transients by blocking the activation of PLC with U-73122 (10 $\mu \mathrm{M}$; Jin et al., 1994). In simultaneous confocal imaging of FM4-64 and Fluo-4 fluorescence ( $n=7$ neurons) this manipulation abolished both submembrane $\mathrm{Ca}^{2+}$ transients and exocytosis upon $20-\mathrm{Hz}$ stimulation. However, the fast $\mathrm{Ca}^{2+}$ transient remained intact (Figures 5C-E).

These results provided two lines of information. On one hand, they confirmed that 5-HT binding to autoreceptors activates PLC and intracellular $\mathrm{Ca}^{2+}$ release. On the other hand, they gave evidence that the small $\mathrm{Ca}^{2+}$ transient is also evoked by the release of small amounts of 5-HT which in our experimental conditions were undetectable as FM dye fluorescence increases. This hypothesis was supported by the presence of vesicles aligned to microtubules that linked vesicle clusters with the plasma membrane. These observations came from 16 electron micrographs obtained from five neurons fixed at rest or after 1-Hz stimulation (Figure 5F, see also Supplementary Figure 1). Therefore, we suppose that an early exocytosis from these vesicles in response to the fast calcium transient produces the small $\mathrm{Ca}^{2+}$ transient while the vesicle clusters arrive at the plasma membrane.

\section{SOMATIC EXOCYTOSIS IS SUSTAINED BY A $\mathrm{Ca}^{2+}$ - AND 5-HT-DEPENDENT POSITIVE FEEDBACK LOOP}

A formal documentation that somatic 5-HT exocytosis is maintained by a positive feedback loop came from plotting the rate of exocytosis (the differential of the FM4-64 fluorescence over time Figures $\left.6 \mathrm{~A}^{\prime}-\mathrm{C}^{\prime}\right)$ vs. the intracellular $\mathrm{Ca}^{2+}$ concentration (the Fluo-4 fluorescence over time). The cyclic shape of the plots shown in Figure 6 is characteristic of a bistable system in a dynamic state, sustained by a positive feedback loop (Gardner et al., 2000; Becskei, 2001; Qu and Vondriska, 2009). A $20 \mathrm{~Hz}$ train switches the system from a resting "off-state" (green traces in Figures $6 \mathrm{~A}^{\prime \prime}, \mathrm{B}^{\prime \prime}$ ) to a dynamic exocytosis "on-state" (purple traces in Figure $6 \mathrm{~A}^{\prime \prime}$ ) by triggering transmembrane $\mathrm{Ca}^{2+}$ entry and exocytosis. The feedback loop operates during the on-state, when the released 5-HT produces the submembrane $\mathrm{Ca}^{2+}$ transients and these transients evoke more exocytosis. The intracellular $\mathrm{Ca}^{2+}$ concentration declines when exocytosis fades out, and the feedback loop ends upon exocytosis from the last vesicles in the cluster (letters " $c$ " and " $c$ " Figure 6). The system goes back to the off-state (letters "d" in Figure 6) when the $\mathrm{Ca}^{2+}$ concentration returns to its basal level (gray interval between " $c$ " and " $\mathrm{d}$ " in Figures $6 A^{\prime \prime}, B^{\prime \prime}$ ).

Those FM4-64 fluorescent spots that displayed a second sigmoidal kinetics also described a second submembrane $\mathrm{Ca}^{2+}$ peak (Figure 6B) and a second dynamic cycle in the plots (Figure 6 $\mathrm{B}^{\prime \prime}$ ). The new cycle expressed a new activation of the feedback loop, thus being consistent with the evidence on the fusion of vesicles arriving in a second cluster (De-Miguel et al., 2012). Note in Figure $\mathbf{6 B}^{\prime \prime}$ that the second cycle started in the absence of new electrical stimulation, when the submembrane $\mathrm{Ca}^{2+}$ concentration was still high and the system remained in the on-state. As expected, when the 5-HT receptors or PLC were blocked (Figures $6 \mathrm{C}-\mathrm{C}^{\prime \prime}$ ) the system could not transit from the off- to the on-state.

\section{DISCUSSION}

We have shown that a brief stimulation with 10 impulses at $20 \mathrm{~Hz}$ produces a fast $\mathrm{Ca}^{2+}$ transient that triggers exocytosis and determines its magnitude. The delayed large-scale exocytosis is then maintained through a positive feedback loop in which the released 5-HT activates 5- $\mathrm{HT}_{2}$ autoreceptors coupled to PLC. This produces a submembrane $\mathrm{Ca}^{2+}$ elevation that triggers more exocytosis. The feedback loop ends upon fusion of the last vesicles in the clusters that arrived at the plasma membrane in response to stimulation. The detailed steps of somatic 5-HT exocytosis shown in this study and complemented with data from our previous work (Trueta et al., 2003, 2004; De-Miguel et al., 2012; Trueta et al., 2012) are summarized in Figure 7.

\section{MULTIPLICITY OF Ca ${ }^{2+}$ EFFECTS ON SOMATIC EXOCYTOSIS}

Summation of $\mathrm{Ca}^{2+}$ entering across the plasma membrane may explain how the stimulation frequency determines the amount of intracellular $\mathrm{Ca}^{2+}$ and exocytosis. The slow inactivation of $\mathrm{L}-$ type channels supports a continuous $\mathrm{Ca}^{2+}$ entry throughout the stimulation train (Nowycky et al., 1985; Fox et al., 1987; Tsien et al., 1988). Since the amplitude of the L-type $\mathrm{Ca}^{2+}$ currents in Retzius neurons remains similar along subsequent impulses 


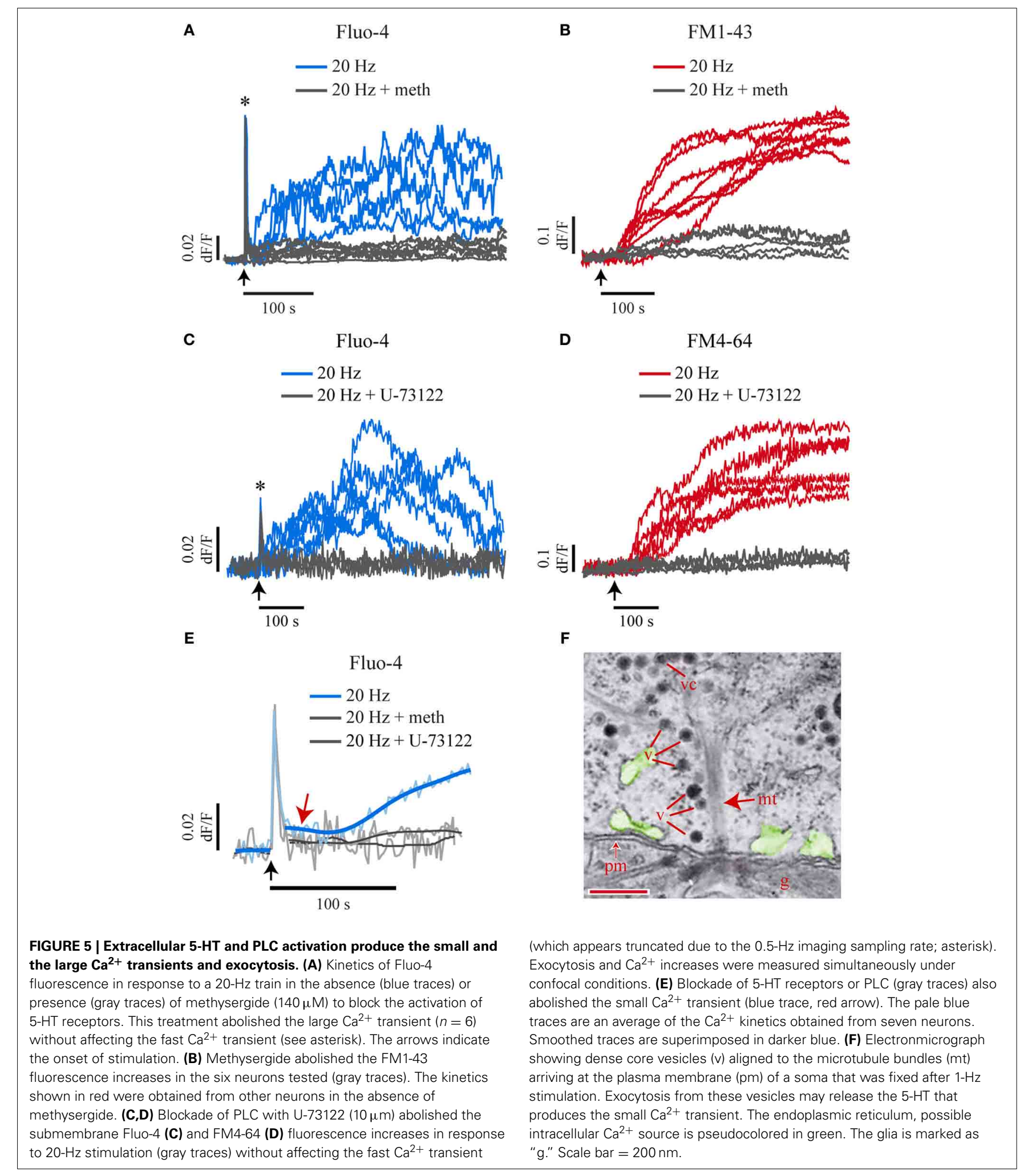

(Ross et al., 1987; Stewart et al., 1989), a temporal summation of the $\mathrm{Ca}^{2+}$ entering the soma upon the successive $20-\mathrm{Hz}$ impulses may produce a rapid and large increase in the $\mathrm{Ca}^{2+}$ concentration as the stimulation frequency is increased. This summation

along with the wide sensitivity to $\mathrm{Ca}^{2+}$ of the ryanodine receptors, which increase their opening probability sigmoidally at $\left[\mathrm{Ca}^{2+}\right]$ between 0.1 and $100 \mu \mathrm{m}$ (Bezprozvanny et al., 1991), explains why increasing the stimulation frequency activates $\mathrm{Ca}^{2+}$-induced 


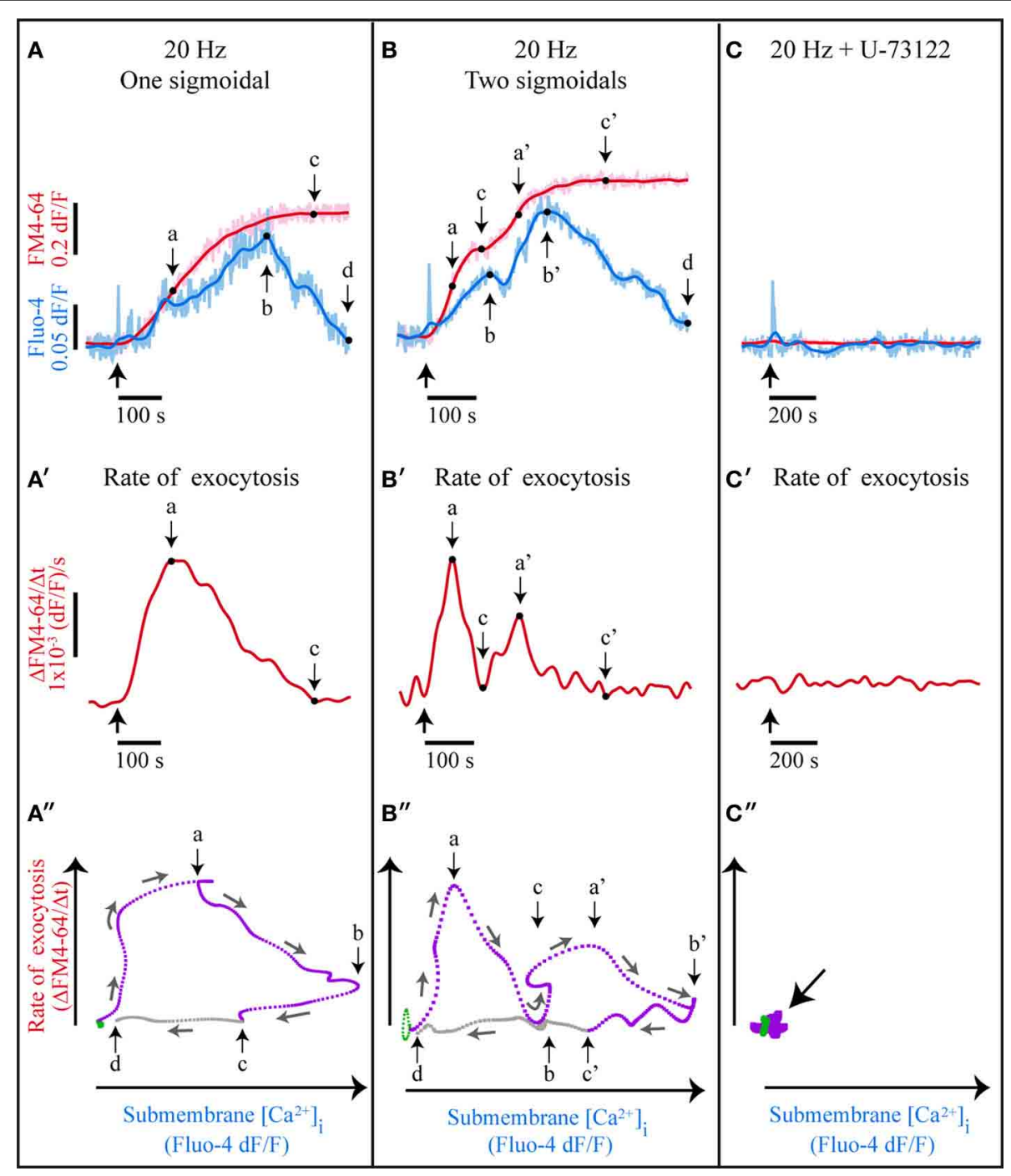

FIGURE 6 | A bistable system with a positive feedback loop sustains somatic exocytosis. (A) Kinetics of simultaneously acquired Fluo-4 (pale blue) and FM4-64 (pink) confocal fluorescence in response to $20-\mathrm{Hz}$ stimulation. The smoothed kinetics are superimposed (dark blue and red traces, respectively). The thick black arrow indicates the stimulation onset; "a" indicates the maximal rate of exocytosis, as estimated from the differential of the kinetics shown in $\left(\mathbf{A}^{\prime}\right)$; " $b$ " is the peak of the large $\mathrm{Ca}^{2+}$ transient; " $\mathrm{C}$ " is the end of exocytosis, when the differential value of the FM4-64 dye fluorescence is zero (see $\mathbf{A}^{\prime}$ ); " $d$ " indicates the end of the large $\mathrm{Ca}^{2+}$ transient. (B) Exocytosis and $\mathrm{Ca}^{2+}$ kinetics displaying two sigmoidal increases upon subsequent exocytosis from two vesicle clusters. The large $\mathrm{Ca}^{2+}$ transient also displays two peaks. " $\mathrm{a}^{\prime}-\mathrm{c}^{\prime}$ " are as in (A), although applied to the second sigmoidal kinetics. (C) In the presence of U-73122 only the fast Fluo-4 transient persisted. ( $\mathbf{A}^{\prime}-\mathbf{C}^{\prime}$ ) Rates of exocytosis obtained from the differential of FM4-64 fluorescence kinetics of the data above. ( $\left.\mathbf{B}^{\prime}\right)$ The rate of exocytosis displays two peaks, each indicating exocytosis from one vesicle cluster. In $\left(\mathbf{C}^{\prime}\right)$ the rate of exocytosis was zero. $\left(\mathbf{A}^{\prime \prime}-\mathbf{C}^{\prime \prime}\right)$ Rate of exocytosis plotted vs. the peak $\mathrm{Ca}^{2+}$ concentration. $\left(\mathbf{A}^{\prime \prime}\right)$ At rest the cells are in an off-state (green) and upon electrical stimulation they transit to a dynamic on-state (purple). The small arrows indicate the time course of the sequence. The feedback loop is active as long as $5-H T$ is released (from the origin of the purple line to point " $c$ "). When $\mathrm{Ca}^{2+}$ returns to its basal levels (point "d") the system returns to the off-state. (B") The rate of exocytosis as a function of the $\mathrm{Ca}^{2+}$ concentration also displays two subsequent cycles. $\left(\mathbf{C}^{\prime \prime}\right)$ blockade of PLC stops the transition from the off to the on-state.
$\mathrm{Ca}^{2+}$ release. A similar combination of transmembrane $\mathrm{Ca}^{2+}$ entry and $\mathrm{Ca}^{2+}$-induced $\mathrm{Ca}^{2+}$ release produces dendrosomatic exocytosis in hypothalamic neurons releasing oxytocin (Ludwig et al., 2002; Tobin et al., 2011, 2012) and in substantia nigra neurons releasing dopamine (Patel et al., 2009), thus suggesting that a similar mechanism operates in those neurons.

Somatic exocytosis in Retzius neurons depends on a microtubule-based vesicle transport (De-Miguel et al., 2012).
Indirect evidence suggests a that a similar phenomenon occurs in other neuron types (Jaffe et al., 1998; Puopolo et al., 2001; Huang et al., 2007; Zhang et al., 2007; Hirasawa et al., 2009; Sarkar et al., 2012). This transport is mediated by molecular motors and therefore somatic exocytosis depends indirectly on ATP synthesis (Bi et al., 1997; Visscher et al., 1999). $\mathrm{Ca}^{2+}$-induced $\mathrm{Ca}^{2+}$ release may then determine the amount of vesicle clusters transported and fused by increasing the intracellular $\mathrm{Ca}^{2+}$ 


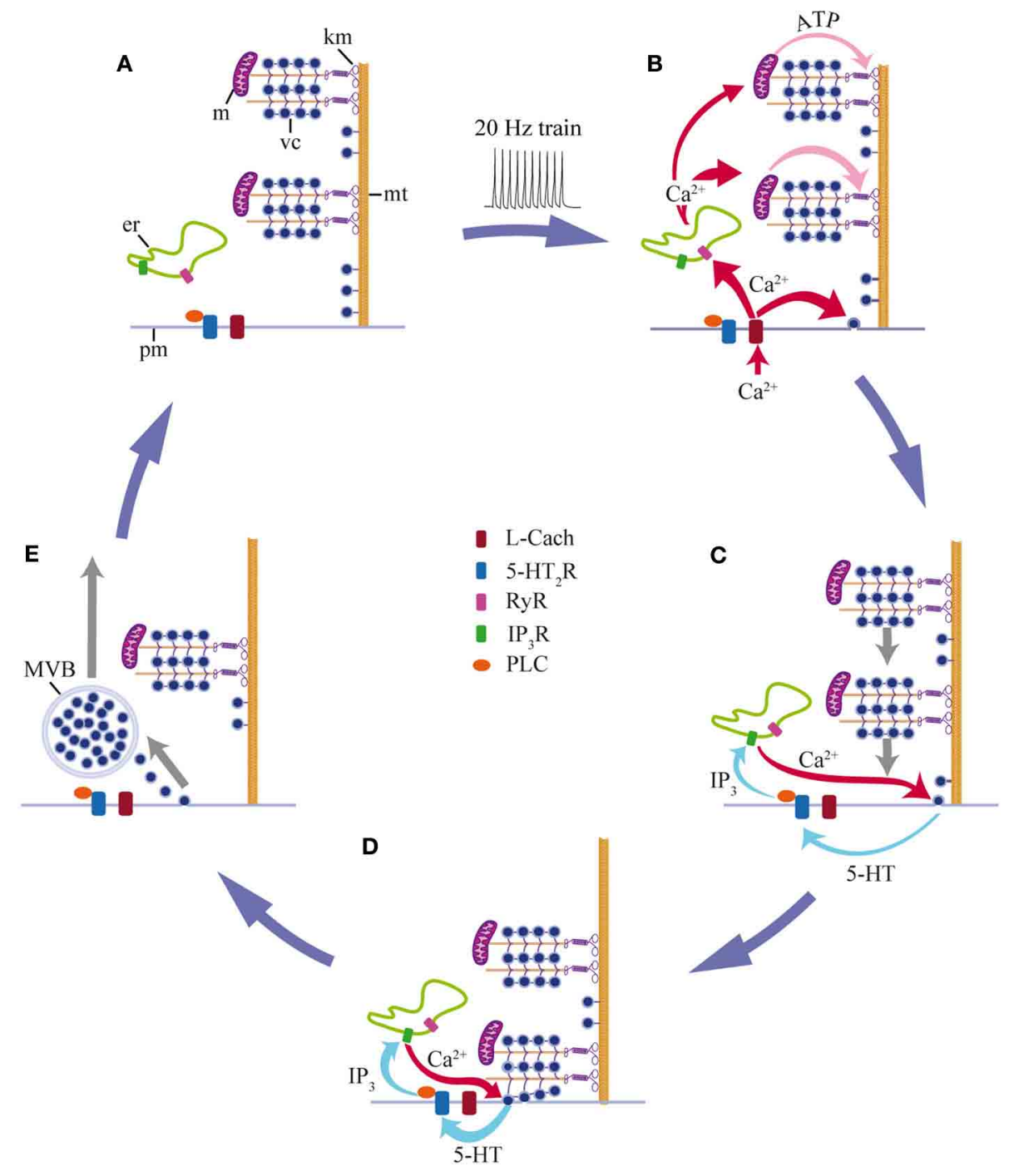

FIGURE 7 | Schematic representation of the mechanism for somatic 5-HT exocytosis by Retzius neurons. (A) At rest, vesicle clusters (vc) and mitochondria $(\mathrm{m})$ are distant from the plasma membrane. Both are attached to microtubules $(\mathrm{mt})$ that arrive at the plasma membrane $(\mathrm{pm})$. Endoplasmic reticulum (er) rests between the plasma membrane and the vesicle clusters (B) A train of impulses evokes transmembrane $\mathrm{Ca}^{2+}$ entry through L-type channels ( $\mathrm{L}$ Cach). $\mathrm{Ca}^{2+}$ triggers exocytosis from vesicles that are close to the plasma membrane and in parallel, $\mathrm{Ca}^{2+}$ entry activates ryanodine receptors (RyR) and $\mathrm{Ca}^{2+}$-induced $\mathrm{Ca}^{2+}$ release, presumably from endoplasmic reticulum. The fast $\mathrm{Ca}^{2+}$ transient reaches the mitochondria (m), which responds by producing ATP. Kinesin motors $(\mathrm{km})$ become activated. (C) Vesicle clusters are transported toward the plasma membrane. The peripheral vesicle clusters and mitochondria receive more $\mathrm{Ca}^{2+}$ and ATP than the central clusters. Therefore, they are transported more efficiently toward the plasma membrane. As vesicles arrive at the plasma membrane and fuse, the released $5-\mathrm{HT}$ activates $5 \mathrm{HT}_{2}$ receptors $\left(5 \mathrm{HT}_{2} \mathrm{R}\right)$ and triggers an intracellular cascade. PLC activation induces $\mathrm{IP}_{3}$ production; $\mathrm{IP}_{3}$ acts on its receptors $\left(I P_{3} \mathrm{R}\right)$ and activates intracellular $\mathrm{Ca}^{2+}$ release from the submembrane endoplasmic reticulum (ER). This $\mathrm{Ca}^{2+}$ evokes more exocytosis, thus closing the local feedback loop. (D) Arrival of the vesicle clusters at the plasma membrane gives place to the large-scale exocytosis. (E) Exocytosis and the feedback loop end when the last vesicles in the cluster fuse. Endocytosis produces multivesicular bodies (MVB) that are transported back to perinuclear regions of the soma (adapted from Trueta et al., 2012). The $\mathrm{Ca}^{2+}$ levels return to rest and the system goes back to its off-state (A). Data from this study are complemented with data from De-Miguel et al. (2012); Trueta et al. (2012). concentration to levels that activate mitochondrial ATP synthesis (Hansford, 1994; Balaban, 2002; Gunter et al., 2004; Satrústegui et al., 2007). In chromaffin cells depolarization and $\mathrm{Ca}^{2+}$ entry also produce the active transport of dense core vesicles before their fusion (Oheim and Stühmer, 2000; Becherer et al., 2003). Also in chromaffin cells dense core vesicles are important sources for $\mathrm{Ca}^{2+}$-induced $\mathrm{Ca}^{2+}$ release (Mitchell et al., 2001; Moreno et al., 2005; Yoo, 2010). However, our results do not support a similar vesicular $\mathrm{Ca}^{2+}$ release in Retzius neurons, since the amplitude of the fast $\mathrm{Ca}^{2+}$ transient in the regions heavily populated with vesicle clusters continues to decay monotonically on its way toward the soma center. As a consequence of the $\mathrm{Ca}^{2+}$ concentration decay as the transient spreads, the peripheral assemblies of mitochondria and vesicle clusters receive more $\mathrm{Ca}^{2+}$ than their equivalents resting more internally. Therefore, the molecular motors associated to these external vesicle clusters would receive 
more newly-synthesized ATP and therefore, they would be more efficiently transported towards the plasma membrane than those clusters resting internally. In this way the number of vesicle clusters transported and fused may be proportional to the amplitude of the fast $\mathrm{Ca}^{2+}$ transient.

\section{THE BEGINNING AND END OF SOMATIC EXOCYTOSIS}

Somatic exocytosis starts when the fast $\mathrm{Ca}^{2+}$ transient triggers exocytosis from small numbers of vesicles resting near the plasma membrane. This exocytosis triggers the feedback loop. A delayed arrival of vesicle clusters at the "activated" release regions produces the large-scale exocytosis by increasing the magnitude of the feedback loop. Therefore, the small and the large $\mathrm{Ca}^{2+}$ transients are expressions of the same phenomenon, namely the 5-HT-and $\mathrm{Ca}^{2+}$-dependent feedback loop that sustains exocytosis. The strict submembrane localization of these $\mathrm{Ca}^{2+}$ transients allows a continuous exocytosis without triggering any further vesicle transport from internal regions. The localization of these transients correlates with the presence of large bags of endoplasmic reticulum near the plasma membrane in electron micrographs. The function of such highly regulated and localized $\mathrm{Ca}^{2+}$ increase prevents a depletion of the somatic 5-HT pool by preventing further activation of vesicle transport from internal somatic regions. However, we have shown that in some cases, a second round of exocytosis occurred in the absence of additional electrical stimulation, provided that the large submembrane $\mathrm{Ca}^{2+}$ transient had not ended. This suggests that a single $20 \mathrm{~Hz}$ train also induces the transport of more distal clusters by the same microtubule rails. In these vesicle clusters approach but do not always reach the plasma membrane, they would constitute the future releasable pool in response to a new train of impulses.

It is interesting that each vesicle cluster functions as an "exocytosis unit" with all its vesicles releasing their content once exocytosis it is triggered, since it allows the all-or-none release of large amounts of 5-HT over long periods. Moreover, exocytosis from the last vesicles in the cluster confers an end to the large-scale exocytosis and to the large $\mathrm{Ca}^{2+}$ transient. A similar phenomenon may occur in the soma of raphe and substancia nigra neurons, in which depolarization induces exocytosis from structures with diameters similar to those of the vesicle clusters of Retzius neurons and also with a similar time course (Sarkar et al., 2012, 2014).

\section{INTEGRATION OF A FEEDBACK SYSTEM TO REGULATE SOMATIC EXOCYTOSIS}

Positive feedback loops constitute dynamic bistable systems which allow a brief stimulus (such as the $20-\mathrm{Hz}$ trains used here) to produce a robust response that may persist over long periods in the absence of any further stimulation ( $\mathrm{Qu}$ and Vondriska, 2009). At the cellular level positive feedback loops contribute to the regulation of intracellular messenger cascades (Gardner et al., 2000; Xiong and Ferrell, 2003; Qu and Vondriska, 2009), the release of hormones (Sabatier et al., 2003; Wintermantel et al., 2006) and cell-to-cell communication in the retina (Jackman et al., 2011). The mechanism presented here is strikingly sophisticated, since it involves multiple steps, the contribution of different intracellular organelles, three $\mathrm{Ca}^{2+}$ sources and events occurring inside and outside the soma. This may be a mechanism of general significance in biology, since in neuroepithelial body cells of rodents; hypoxia produces a 5 -HT- and $\mathrm{Ca}^{2+}$-dependent increase in 5-HT release (Fu et al., 2002). Moreover, in dendrites of hypothalamic neurons the activation of dendritic oxytocin autoreceptors elevates the intracellular $\mathrm{Ca}^{2+}$ concentration and triggers exocytosis from dense core vesicles (Lambert et al., 1994; Neumann et al., 1996; Ludwig and Leng, 2006).

\section{PHYSIOLOGICAL IMPORTANCE OF SOMATIC EXOCYTOSIS FOR SEROTONERGIC SYSTEMS}

The 5-HT modulation of circuits and behaviors along phylogeny requires large amounts of transmitter molecules acting at different levels of the nervous system (Saller and Stricker, 1976; Willard, 1981; Lent, 1985; Raleigh et al., 1991; Gillette et al., 1993; Barnes and Jacklet, 1997; Hull et al., 1999; Kravitz, 2000; Prosser, 2003; Alekseyenko et al., 2010; Tomioka et al., 2012). Somatic exocytosis seems particularly well fitted for this function. In the leech, electrical stimulation of Retzius neurons with high-frequency trains of impulses increases the levels of extracellular 5-HT in the ganglion and in the blood (Willard, 1981). This stimulation also produces a non-synaptic 5-HT activation of the swimming circuit (Nusbaum and Kristan, 1986), thus suggesting that it occurs in response to somatic and maybe axonal 5-HT release. In mammals, serotonergic neurons innervate most of the central nervous system (Jacobs and Azmitia, 1992) and 5 -HT is released through somatic and dendritic exocytosis (De Kock et al., 2006; Kaushalya et al., 2008; Colgan et al., 2009, 2012; Sarkar et al., 2012). This release in addition to the small numbers of presynaptic terminals formed by serotonergic neurons (Mosko et al., 1977; Héry and Ternaux, 1981; Chazal and Ralston, 1987; Marlier et al., 1991; Ridet et al., 1993; Moukhles et al., 1997) suggests that somatic and in general extrasynaptic exocytosis is a major player of 5-HT communication (Agnati et al., 1986; De-Miguel and Fuxe, 2012; Fuxe et al., 2012; Trueta and De-Miguel, 2012). It was already mentioned that the soma of raphe neurons releases 5-HT for long periods from structures that may be similar to the clusters shown here (Kaushalya et al., 2008; Sarkar et al., 2012). In addition, the dendrites and axons of these neurons contain clear and dense core vesicles in arrangements suitable to produce extrasynaptic exocytosis (Kapadia et al., 1985; Liposits et al., 1985; Chazal and Ralston, 1987; Ridet et al., 1993; Van Bockstaele and Pickel, 1993; Bunin and Wightman, 1999; Descarries and Mechawar, 2000). Moreover, in these neurons the activation of L-type channels evokes dendritic exocytosis (Colgan et al., 2012). These evidences suggest that the mechanism shown here may also operate at smaller volume- and time-scales in dendrites and axons of mammalian serotonergic neurons. Such idea is consistent with the $5 \mathrm{~s}$ latency of 5-HT extracellular increases upon dendro-somatic stimulation in rat brain slices (Bunin and Wightman, 1998).

It is interesting to note that 5-HT autoreceptors are typically inhibitory and belong to the $5-\mathrm{HT}_{1}$ type (for review see Barnes and Sharp, 1999). However, the autoreceptors involved in the positive feedback system shown here are of the $5-\mathrm{HT}_{2}$-type, according to their pharmacological profile and intracellular metabolic cascade (Drapeau et al., 1989; Sanchez-Armass et al., 
1991; Barnes and Sharp, 1999). The incorporation of this type of receptor may be an adaptation of somatic exocytosis, since presynaptic terminals formed by Retzius neurons contain the characteristic $5-\mathrm{HT}_{1}$ type receptors that inhibit electrical activity and transmitter release (Cercós et al., 2009), similar to their function in mammals (Chaput et al., 1986; Trulson and Frederickson, 1987; O'Connor and Kruk, 1991; Fornal et al., 1994).

Two additional aspects are worth discussing. One is that the decay time course of the large submembrane $\mathrm{Ca}^{2+}$ transient may be due, at least in part, to the removal of 5-HT from the extracellular space. The other is that 5-HT release in the intact nervous system occurs onto the extracellular space which is tightly surrounded by a giant glial cell (Coggeshall and Fawcett, 1964; Kuffler and Nicholls, 1966; see also Supplementary Figure 1). Since this glial cell has 5-HT an uptake system (Bruns et al., 1993), it may contribute to the 5-HT removal from the extracellular space. Therefore, these transporters may modulate the duration of exocytosis. On the other hand, the virtual isolation of the soma of the Retzius neuron by the glial sheets suggests that the 5-HT uptake participates in the distribution of 5-HT to other sites of the nervous system.

\section{GENERAL SIGNIFICANCE}

Somatic exocytosis is a widespread mechanism for paracrine communication in the nervous system (De-Miguel and Fuxe, 2012; Fuxe et al., 2012; Trueta and De-Miguel, 2012), and evidence suggests that transmitters released in this way modulate the activity of neurons, glia and blood vessels (Fuxe et al., 1988; Descarries and Mechawar, 2000; Jansson et al., 2001; Del Arco et al., 2003; Fuxe et al., 2010; Thyssen et al., 2010; De-Miguel and Fuxe, 2012). The similar duration of somatic exocytosis in several neuron types (De-Miguel and Fuxe, 2012; Trueta and De-Miguel, 2012) suggest that somatic exocytosis it is ruled by a similar mechanism. Therefore, the findings presented here may be of general interest to explain the cellular basis of paracrine communication in the nervous system.

\section{AUTHOR CONTRIBUTIONS}

The author(s) have made the following declarations about their contributions: Carolina Leon-Pinzon and Francisco F. DeMiguel conceived and designed the experiments. Carolina LeonPinzon, Montserrat G. Cercós, Paula Noguez and FFM performed the experiments. Carolina Leon-Pinzon, Montserrat G. Cercós, Citlali Trueta and Francisco F. De-Miguel analyzed the data. Francisco F. De-Miguel and Citlali Trueta contributed reagents/materials/analysis tools. Francisco F. De-Miguel and Carolina Leon-Pinzon wrote the paper.

\section{ACKNOWLEDGMENTS}

We wish to express our gratitude to Mr. Bruno Mendez for his invaluable technical help in different stages of these investigations and to Sara Flores González for excellent assistance in the animal care. We also wish to acknowledge the electron microscopy and computer units of IFC-UNAM, in particular Dr. Fernando García Hernández, Rodolfo Paredes and Francisco Pérez, for their outstanding technical support. Ricardo Cruz Garduño gave invaluable graphic assistance to Figure 7. Professor
David Weisblat made important comments to the manuscript. This work was founded by a DGAPA-UNAM grant IN200914 and a CONACYT GRANT 130031 to Francisco F. De-Miguel. Carolina Leon-Pinzon was supported by a CONACyT doctoral fellowship 230099, a CONACyT fellowship from grant 130031 and a by a DGAPA-UNAM fellowship from grant IN211511 and IN200914 to Francisco F. De-Miguel. Montserrat G. Cercós was supported by CONACyT doctoral fellowship 220728 and Paula Noguez was supported by CONACyT doctoral fellowship 193987. This paper is part of the Ph.D. thesis of Carolina Leon-Pinzon who is ascribed to the Doctorado en Ciencias Biomédicas of Universidad Nacional Autónoma de México (UNAM). The funders had no role in study design, data collection and analysis, decision to publish, or preparation of the manuscript.

\section{SUPPLEMENTARY MATERIAL}

The Supplementary Material for this article can be found online at: http://www.frontiersin.org/journal/10.3389/fncel.2014. 00169/abstract

\section{REFERENCES}

Agnati, L. F., Fuxe, K., Zoli, M., Ozini, I., Toffano, G., and Ferraguti, F. (1986). A correlation analysis of the regional distribution of central enkephalin and betaendorphin immunoreactive terminals and of opiate receptors in adult and old male rats. Evidence for the existence of two main types of communication in the central nervous system: the volume transmission and the wiring transmission. Acta Physiol. Scand. 128, 201-207. doi: 10.1111/j.1748-1716.1986.tb07967.x

Alekseyenko, O. V., Lee, C., and Kravitz, E. A. (2010). Targeted manipulation of serotonergic neurotransmission affects the escalation of aggression in adult male Drosophila melanogaster. PLoS ONE 5:e10806. doi: 10.1371/journal.pone.0010806

Augustine, G. J., and Neher, E. (1992). Calcium requirements for secretion in bovine chromaffin cells. J. Physiol. 450, 247-271.

Balaban, R. S. (2002). Cardiac energy metabolism homeostasis: role of cytosolic calcium. J. Mol. Cell. Cardiol. 34, 1259-1271. doi: 10.1016/S0022-2828(02)92082-1

Barnes, N. M., and Sharp, T. (1999). A review of central 5-HT receptors and their function. Neuropharmacology 38, 1083-1152. doi: 10.1016/S00283908(99)00010-6

Barnes, S., and Jacklet, J. W. (1997). Ionic currents of isolated retinal pacemaker neurons: projected daily phase differences and selective enhancement by a phase-shifting neurotransmitter. J. Neurophysiol. 77, 3075-3084.

Becherer, U., Moser, T., Stühmer, W., and Oheim, M. (2003). Calcium regulates exocytosis at the level of single vesicles. Nat. Neurosci. 6, 846-853. doi: 10.1038/nn1087

Beck, A., Lohr, C., Berthold, H., and Deitmer, J. W. (2002). Calcium influx into dendrites of the leech Retzius neuron evoked by 5-hydroxytryptamine. Cell Calcium 31, 137-149. doi: 10.1054/ceca.2001.0268

Becskei, A. (2001). Positive feedback in eukaryotic gene networks: cell differentiation by graded to binary response conversion. EMBO J. 20, 2528-2535. doi: $10.1093 /$ emboj/20.10.2528

Betz, W. J., and Bewick, G. S. (1992). Optical analysis of synaptic vesicle recycling at the frog neuromuscular junction. Science 255, 200-203. doi: 10.1126/science. 1553547

Bezprozvanny, I., Watras, J., and Ehrlich, B. E. (1991). Bell-shaped calciumresponse curves of Ins $(1,4,5) \mathrm{P} 3$ - and calcium-gated channels from endoplasmic reticulum of cerebellum. Nature 351, 751-754. doi: 10.1038/351751a0

Bi, G. Q., Morris, R. L., Liao, G., Alderton, J. M., Scholey, J. M., and Steinhardt, R. A. (1997). Kinesin- and myosin-driven steps of vesicle recruitment for Ca2+regulated exocytosis. J. Cell Biol. 138, 999-1008. doi: 10.1083/jcb.138.5.999

Bruns, D., Engert, F., and Lux, H. D. (1993). A fast activating presynaptic reuptake current during serotonergic transmission in identified neurons of Hirudo. Neuron 10, 559-572. doi: 10.1016/0896-6273(93)90159-O

Bruns, D., Riedel, D., Klingauf, J., and Jahn, R. (2000). Quantal release of serotonin. Neuron 28, 205-220. doi: 10.1016/S0896-6273(00)00097-0 
Bunin, M. A., and Wightman, R. M. (1998). Quantitative evaluation of 5hydroxytryptamine (serotonin) neuronal release and uptake: an investigation of extrasynaptic transmission. J. Neurosci. 18, 4854-4860.

Bunin, M. A., and Wightman, R. M. (1999). Paracrine neurotransmission in the CNS: involvement of 5-HT. Trends Neurosci. 22, 377-382. doi: 10.1016/S01662236(99)01410-1

Cercós, M. G., De-Miguel, F. F., and Trueta, C. (2009). Real-time measurements of synaptic autoinhibition produced by serotonin release in cultured leech neurons. J. Neurophysiol. 102, 1075-1085. doi: 10.1152/jn.00107.2009

Chaput, Y., Blier, P., and de Montigny, C. (1986). In vivo electrophysiological evidence for the regulatory role of autoreceptors on serotonergic terminals. J. Neurosci. 6, 2796-2801.

Chazal, G., and Ralston, H. J. 3rd. (1987). Serotonin-containing structures in the nucleus raphe dorsalis of the cat: an ultrastructural analysis of dendrites, presynaptic dendrites, and axon terminals. J. Comp. Neurol. 259, 317-329. doi: $10.1002 /$ cne. 902590302

Chen, G., Gutman, D. A., Zerby, S. E., and Ewing, A. G. (1996). Electrochemical monitoring of bursting exocytotic events from the giant dopamine neuron of Planorbis corneus. Brain Res. 733, 119-124. doi: 10.1016/S00068993(96)00754-8

Chow, R. H., Klingauf, J., Heinemann, C., Zucker, R. S., and Neher, E. (1996). Mechanisms determining the time course of secretion in neuroendocrine cells. Neuron 16, 369-376. doi: 10.1016/S0896-6273(00)80054-9

Coggeshall, R. E. (1972). Autoradiographic and chemical localization of 5hydroxytryptamine in identified neurons in the leech. Anat. Rec. 172, 489-498. doi: 10.1002/ar.1091720303

Coggeshall, R. E., and Fawcett, D. W. (1964). The fine structure of the central nervous system of the leech, Hirudo Medicinalis. J. Neurophysiol. 27, 229-289.

Colgan, L. A., Cavolo, S. L., Commons, K. G., and Levitan, E. S. (2012). Action potential-independent and pharmacologically unique vesicular serotonin release from dendrites. J. Neurosci. 32, 15737-15746. doi: 10.1523/JNEUROSCI.0020-12.2012

Colgan, L. A., Putzier, I., and Levitan, E. S. (2009). Activity-dependent vesicular monoamine transporter-mediated depletion of the nucleus supports somatic release by serotonin neurons. J. Neurosci. 29, 15878-15887. doi: 10.1523/JNEUROSCI.4210-09.2009

De Kock, C. P. J., Cornelisse, L. N., Burnashev, N., Lodder, J. C., Timmerman, A. J., Couey, J. J., et al. (2006). NMDA receptors trigger neurosecretion of 5-HT within dorsal raphe nucleus of the rat in the absence of action potential firing. J. Physiol. 577, 891-905. doi: 10.1113/jphysiol.2006.115311

Del Arco, A., Segovia, G., Fuxe, K., and Mora, F. (2003). Changes in dialysate concentrations of glutamate and GABA in the brain: an index of volume transmission mediated actions? J. Neurochem. 85, 23-33. doi: 10.1046/j.14714159.2003.01692.x

De-Miguel, F. F., and Fuxe, K. (2012). Extrasynaptic neurotransmission as a way of modulating neuronal functions. Front. Physiol. 3:16. doi: $10.3389 /$ fphys.2012.00016

De-Miguel, F. F., Santamaría-Holek, I., Noguez, P., Bustos, C., Hernández-Lemus, E., and Rubí, J. M. (2012). Biophysics of active vesicle transport, an intermediate step that couples excitation and exocytosis of serotonin in the neuronal soma. PLoS ONE 7:e45454. doi: 10.1371/journal.pone.0045454

De-Miguel, F. F., and Trueta, C. (2005). Synaptic and extrasynaptic secretion of serotonin. Cell. Mol. Neurobiol. 25, 297-312. doi: 10.1007/s10571-005-3061-z

Descarries, L., and Mechawar, N. (2000). Ultrastructural evidence for diffuse transmission by monoamine and acetylcholine neurons of the central nervous system. Prog. Brain Res. 125, 27-47. doi: 10.1016/S0079-6123(00)25005-X

Dietzel, I. D., Drapeau, P., and Nicholls, J. G. (1986). Voltage dependence of 5hydroxytryptamine release at a synapse between identified leech neurones in culture. J. Physiol. 372, 191-205.

Drapeau, P., Melinyshyn, E., and Sanchez-Armass, S. (1989). Contact-mediated loss of the nonsynaptic response to transmitter during reinnervation of an identified leech neuron in culture. J. Neurosci. 9, 2502-2508.

Fernandez-De-Miguel, F., Cooper, R. L., and Adams, W. B. (1992). Synaptogenesis and calcium current distribution in cultured leech neurons. Proc. R. Soc. B Biol. Sci. 247, 215-221. doi: 10.1098/rspb.1992.0032

Fornal, C. A., Litto, W. J., Metzler, C. W., Marrosu, F., Tada, K., and Jacobs, B. L. (1994). Single-unit responses of serotonergic dorsal raphe neurons to 5-HT1A agonist and antagonist drug administration in behaving cats. J. Pharmacol. Exp. Ther. 270, 1345-1358.
Fox, A. P., Nowycky, M. C., and Tsien, R. W. (1987). Single-channel recordings of three types of calcium channels in chick sensory neurones. J. Physiol. 394, 173-200.

Fu, X. W., Nurse, C. A., Wong, V., and Cutz, E. (2002). Hypoxia-induced secretion of serotonin from intact pulmonary neuroepithelial bodies in neonatal rabbit. J. Physiol. 539, 503-510. doi: 10.1113/jphysiol.2001.013071

Fuxe, K., Borroto-Escuela, D. O., Romero-Fernandez, W., Diaz-Cabiale, Z., Rivera, A., Ferraro, L., et al. (2012). Extrasynaptic neurotransmission in the modulation of brain function. Focus on the striatal neuronal-glial networks. Front. Physiol. 3:136. doi: 10.3389/fphys.2012.00136

Fuxe, K., Cintra, A., Agnati, L. F., Härfstrand, A., and Goldstein, M. (1988). Studies on the relationship of tyrosine hydroxylase, dopamine and cyclic amp-regulated phosphoprotein-32 immunoreactive neuronal structures and $\mathrm{d} 1$ receptor antagonist binding sites in various brain regions of the male rat-mismatches indicate a role of $\mathrm{d} 1$ receptors in volume transmission. Neurochem. Int. 13, 179-197. doi: 10.1016/0197-0186(88)90054-X

Fuxe, K., Dahlström, A. B., Jonsson, G., Marcellino, D., Guescini, M., Dam, M., et al. (2010). The discovery of central monoamine neurons gave volume transmission to the wired brain. Prog. Neurobiol. 90, 82-100. doi: 10.1016/j.pneurobio.2009.10.012

Gardner, T. S., Cantor, C. R., and Collins, J. J. (2000). Construction of a genetic toggle switch in Escherichia coli. Nature 403, 339-342. doi: 10.1038/35002131

Gee, K. R., Brown, K. A., Chen, W. N., Bishop-Stewart, J., Gray, D., and Johnson, I. (2000). Chemical and physiological characterization of fluo-4 $\mathrm{Ca}(2+)$-indicator dyes. Cell Calcium 27, 97-106. doi: 10.1054/ceca.1999.0095

Gillette, M. U., DeMarco, S. J., Ding, J. M., Gallman, E. A., Faiman, L. E., Liu, C., et al. (1993). The organization of the suprachiasmatic circadian pacemaker of the rat and its regulation by neurotransmitters and modulators. J. Biol. Rhythms 8(Suppl.), S53-S58.

Gunter, T. E., Yule, D. I., Gunter, K. K., Eliseev, R. A., and Salter, J. D. (2004). Calcium and mitochondria. FEBS Lett. 567, 96-102. doi: 10.1016/j.febslet.2004.03.071

Hansford, R. G. (1994). Physiological role of mitochondrial Ca2+ transport. J. Bioenerg. Biomembr. 26, 495-508. doi: 10.1007/BF00762734

Héry, F., and Ternaux, J. P. (1981). Regulation of release processes in central serotoninergic neurons. J. Physiol. 77, 287-301.

Hirasawa, H., Puopolo, M., and Raviola, E. (2009). Extrasynaptic release of GABA by retinal dopaminergic neurons. J. Neurophysiol. 102, 146-158. doi: 10.1152/jn.00130.2009

Huang, H.-P., Wang, S.-R., Yao, W., Zhang, C., Zhou, Y., Chen, X.-W., et al. (2007). Long latency of evoked quantal transmitter release from somata of locus coeruleus neurons in rat pontine slices. Proc. Natl. Acad. Sci. U.S.A. 104, 1401-1406. doi: 10.1073/pnas.0608897104

Hull, E. M., Lorrain, D. S., Du, J., Matuszewich, L., Lumley, L. A., Putnam, S. K., et al. (1999). Hormone-neurotransmitter interactions in the control of sexual behavior. Behav. Brain Res. 105, 105-116. doi: 10.1016/S0166-4328(99) 00086-8

Jackman, S. L., Babai, N., Chambers, J. J., Thoreson, W. B., and Kramer, R. H. (2011). A positive feedback synapse from retinal horizontal cells to cone photoreceptors. PLoS Biol. 9:e1001057. doi: 10.1371/journal.pbio.1001057

Jacobs, B. L., and Azmitia, E. C. (1992). Structure and function of the brain serotonin system. Physiol. Rev. 72, 165-229.

Jaffe, E. H., Marty, A., Schulte, A., and Chow, R. H. (1998). Extrasynaptic vesicular transmitter release from the somata of substantia nigra neurons in rat midbrain slices. J. Neurosci. 18, 3548-3553.

Jansson, A., Tinner, B., Bancila, M., Vergé, D., Steinbusch, H. W., Agnati, L. F., et al. (2001). Relationships of 5-hydroxytryptamine immunoreactive terminallike varicosities to 5-hydroxytryptamine-2A receptor-immunoreactive neuronal processes in the rat forebrain. J. Chem. Neuroanat. 22, 185-203. doi: 10.1016/S0891-0618(01)00133-8

Jin, W., Lo, T. M., Loh, H. H., and Thayer, S. A. (1994). U73122 inhibits phospholipase C-dependent calcium mobilization in neuronal cells. Brain Res. 642, 237-243. doi: 10.1016/0006-8993(94)90927-X

Kapadia, S. E., de Lanerolle, N. C., and LaMotte, C. C. (1985). Immunocytochemical and electron microscopic study of serotonin neuronal organization in the dorsal raphe nucleus of the monkey. Neuroscience 15, 729-746. doi: 10.1016/0306-4522(85)90075-2

Kaushalya, S. K., Desai, R., Arumugam, S., Ghosh, H., Balaji, J., and Maiti, S. (2008). Three-photon microscopy shows that somatic release can be a quantitatively 
significant component of serotonergic neurotransmission in the mammalian brain. J. Neurosci. Res. 86, 3469-3480. doi: 10.1002/jnr.21794

Klingauf, J., and Neher, E. (1997). Modeling buffered Ca2+ diffusion near the membrane. Biophys. J. 72, 674-690. doi: 10.1016/S0006-3495(97) 78704-6

Kravitz, E. A. (2000). Serotonin and aggression: insights gained from a lobster model system and speculations on the role of amine neurons in a complex behavior. J. Comp. Physiol. A 186, 221-238. doi: 10.1007/s003590050423

Kuffler, D. P., Nicholls, J., and Drapeau, P. (1987). Transmitter localization and vesicle turnover at a serotoninergic synapse between identified leech neurons in culture. J. Comp. Neurol. 256, 516-526. doi: 10.1002/cne.902560404

Kuffler, S. W., and Nicholls, J. G. (1966). The physiology of neuroglial cells. Erg. Physiol. Biol. Chem. Exp. Pharmakol. 57, 1-90. doi: 10.1007/BF02259903

Lambert, R. C., Dayanithi, G., Moos, F. C., and Richard, P. (1994). A rise in the intracellular $\mathrm{Ca} 2+$ concentration of isolated rat supraoptic cells in response to oxytocin. J. Physiol. 478(Pt 2), 275-287.

Lent, C. M. (1985). Serotonergic modulation of the feeding behavior of the medicinal leech. Brain Res. Bull. 14, 643-655. doi: 10.1016/0361-9230(85)90114-5

Lessmann, V., and Dietzel, I. D. (1991). Development of serotonin-induced ion currents in identified embryonic Retzius cells from the medicinal leech (Hirudo medicinalis). J. Neurosci. 11, 800-809.

Liposits, Z., Görcs, T., and Trombitás, K. (1985). Ultrastructural analysis of central serotoninergic neurons immunolabeled by silver-gold-intensified diaminobenzidine chromogen. Completion of immunocytochemistry with X-ray microanalysis. J. Histochem. Cytochem. 33, 604-610. doi: 10.1177/33.6.3889144

Ludwig, M., and Leng, G. (2006). Dendritic peptide release and peptide-dependent behaviours. Nat. Rev. Neurosci. 7, 126-136. doi: 10.1038/nrn1845

Ludwig, M., Sabatier, N., Bull, P. M., Landgraf, R., Dayanithi, G., and Leng, G. (2002). Intracellular calcium stores regulate activity-dependent neuropeptide release from dendrites. Nature 418, 85-89. doi: 10.1038/nature00822

Marlier, L., Sandillon, F., Poulat, P., Rajaofetra, N., Geffard, M., and Privat, A. (1991). Serotonergic innervation of the dorsal horn of rat spinal cord: light and electron microscopic immunocytochemical study. J. Neurocytol. 20, 310-322. doi: 10.1007/BF01235548

Mitchell, K. J., Pinton, P., Varadi, A., Tacchetti, C., Ainscow, E. K., Pozzan, T., et al. (2001). Dense core secretory vesicles revealed as a dynamic $\mathrm{Ca}(2+)$ store in neuroendocrine cells with a vesicle-associated membrane protein aequorin chimaera. J. Cell Biol. 155, 41-51. doi: 10.1083/jcb.200103145

Moreno, A., Lobatón, C. D., Santodomingo, J., Vay, L., Hernández-SanMiguel, E., Rizzuto, R., et al. (2005). Calcium dynamics in catecholamine-containing secretory vesicles. Cell Calcium 37, 555-564. doi: 10.1016/j.ceca.2005. 02.002

Mosko, S. S., Haubrich, D., and Jacobs, B. L. (1977). Serotonergic afferents to the dorsal raphe nucleus: evdience from HRP and synaptosomal uptake studies. Brain Res. 119, 269-290. doi: 10.1016/0006-8993(77)90311-0

Moukhles, H., Bosler, O., Bolam, J., Vallée, A., Umbriaco, D., Geffard, M., et al. (1997). Quantitative and morphometric data indicate precise cellular interactions between serotonin terminals and postsynaptic targets in rat substantia nigra. Neuroscience 76, 1159-1171. doi: 10.1016/S0306-4522(96)00452-6

Neher, E., and Augustine, G. J. (1992). Calcium gradients and buffers in bovine chromaffin cells. J. Physiol. 450, 273-301.

Neumann, I., Douglas, A. J., Pittman, Q. J., Russell, J. A., and Landgraf, R. (1996). Oxytocin released within the supraoptic nucleus of the rat brain by positive feedback action is involved in parturition-related events. J. Neuroendocrinol. 8, 227-233. doi: 10.1046/j.1365-2826.1996.04557.x

Nicholls, J. G., and Kuffler, D. P. (1990). Quantal release of serotonin from presynaptic nerve terminals. Neurochem. Int. 17, 157-163. doi: 10.1016/01970186(90)90138-J

Nowycky, M. C., Fox, A. P., and Tsien, R. W. (1985). Three types of neuronal calcium channel with different calcium agonist sensitivity. Nature 316, 440-443. doi: $10.1038 / 316440 \mathrm{a} 0$

Nusbaum, M. P., and Kristan, W. B. Jr. (1986). Swim initiation in the leech by serotonin-containing interneurones, cells 21 and 61. J. Exp. Biol. 122, 277-302.

O'Connor, J. J., and Kruk, Z. L. (1991). Frequency dependence of 5-HT autoreceptor function in rat dorsal raphe and suprachiasmatic nuclei studied using fast cyclic voltammetry. Brain Res. 568, 123-130. doi:10.1016/0006-8993(91) 91387-G

Oheim, M., and Stühmer, W. (2000). Tracking chromaffin granules on their way through the actin cortex. Eur. Biophys. J. 29, 67-89. doi: 10.1007/s002490050253
Pandey, S. C., Davis, J. M., and Pandey, G. N. (1995). Phosphoinositide system-linked serotonin receptor subtypes and their pharmacological properties and clinical correlates. J. Psychiatry Neurosci. 20, 215-225.

Patel, J. C., Witkovsky, P., Avshalumov, M. V., and Rice, M. E. (2009). Mobilization of calcium from intracellular stores facilitates somatodendritic dopamine release. J. Neurosci. 29, 6568-6579. doi: 10.1523/JNEUROSCI.0181-09.2009

Pozzan, T., Rizzuto, R., Volpe, P., and Meldolesi, J. (1994). Molecular and cellular physiology of intracellular calcium stores. Physiol. Rev. 74, 595-636.

Prosser, R. A. (2003). Serotonin phase-shifts the mouse suprachiasmatic circadian clock in vitro. Brain Res. 966, 110-115. doi: 10.1016/S0006-8993(02)04206-3

Puopolo, M., Hochstetler, S. E., Gustincich, S., Wightman, R. M., and Raviola, E. (2001). Extrasynaptic release of dopamine in a retinal neuron: activity dependence and transmitter modulation. Neuron 30, 211-225. doi: 10.1016/S08966273(01)00274-4

Qu, Z., and Vondriska, T. M. (2009). The effects of cascade length, kinetics and feedback loops on biological signal transduction dynamics in a simplified cascade model. Phys. Biol. 6:016007. doi: 10.1088/1478-3975/6/1/016007

Raleigh, M. J., McGuire, M. T., Brammer, G. L., Pollack, D. B., and Yuwiler, A. (1991). Serotonergic mechanisms promote dominance acquisition in adult male vervet monkeys. Brain Res. 559, 181-190. doi: 10.1016/0006-8993(91)90001-C

Ridet, J. L., Rajaofetra, N., Teilhac, J. R., Geffard, M., and Privat, A. (1993). Evidence for nonsynaptic serotonergic and noradrenergic innervation of the rat dorsal horn and possible involvement of neuron-glia interactions. Neuroscience 52, 143-157. doi: 10.1016/0306-4522(93)90189-M

Ross, W. N., Arechiga, H., and Nicholls, J. G. (1987). Optical recording of calcium and voltage transients following impulses in cell bodies and processes of identified leech neurons in culture. J. Neurosci. 7, 3877-3887.

Sabatier, N., Caquineau, C., Douglas, A. J., and Leng, G. (2003). Oxytocin released from magnocellular dendrites: a potential modulator of alpha-melanocytestimulating hormone behavioral actions? Ann. N. Y. Acad. Sci. 994, 218-224. doi: 10.1111/j.1749-6632.2003.tb03183.x

Sabatini, B. L., and Regehr, W. G. (1998). Optical measurement of presynaptic calcium currents. Biophys. J. 74, 1549-1563. doi: 10.1016/S0006-3495(98)77867-1

Sala, F., and Hernández-Cruz, A. (1990). Calcium diffusion modeling in a spherical neuron. Relevance of buffering properties. Biophys. J. 57, 313-324. doi: 10.1016/S0006-3495(90)82533-9

Saller, C. F., and Stricker, E. M. (1976). Hyperphagia and increased growth in rats after intraventricular injection of 5,7-dihydroxytryptamine. Science 192, 385-387. doi: 10.1126/science. 1257774

Sanchez-Armass, S., Merz, D. C., and Drapeau, P. (1991). Distinct receptors, second messengers and conductances underlying the dual responses to serotonin in an identified leech neurone. J. Exp. Biol. 155, 531-547.

Sarkar, B., Banerjee, A., Das, A. K., Nag, S., Kaushalya, S. K., Tripathy, U., et al. (2014). Label-free dopamine imaging in live rat brain slices. ACS Chem. Neurosci. 5, 329-334. doi: 10.1021/cn5000138

Sarkar, B., Das, A. K., Arumugam, S., Kaushalya, S. K., Bandyopadhyay, A., Balaji, J., et al. (2012). The dynamics of somatic exocytosis in monoaminergic neurons. Front. Physiol. 3:414. doi: 10.3389/fphys.2012.00414

Satrústegui, J., Pardo, B., and Del Arco, A. (2007). Mitochondrial transporters as novel targets for intracellular calcium signaling. Physiol. Rev. 87, 29-67. doi: 10.1152/physrev.00005.2006

Siddall, M. E., Trontelj, P., Utevsky, S. Y., Nkamany, M., and Macdonald, K. S. (2007). Diverse molecular data demonstrate that commercially available medicinal leeches are not Hirudo medicinalis. Proc. R. Soc. B Biol. Sci. 274, 1481-1487. doi: 10.1098/rspb.2007.0248

Soldo, B. L., Giovannucci, D. R., Stuenkel, E. L., and Moises, H. C. (2004). Ca(2+) and frequency dependence of exocytosis in isolated somata of magnocellular supraoptic neurones of the rat hypothalamus. J. Physiol. 555, 699-711. doi: 10.1113/jphysiol.2003.051136

Stewart, R. R., Adams, W. B., and Nicholls, J. G. (1989). Presynaptic calcium currents and facilitation of serotonin release at synapses between cultured leech neurones. J. Exp. Biol. 144, 1-12.

Sun, Y. A., and Poo, M. M. (1987). Evoked release of acetylcholine from the growing embryonic neuron. Proc. Natl. Acad. Sci. U.S.A. 84, 2540-2544. doi: 10.1073/pnas.84.8.2540

Thyssen, A., Hirnet, D., Wolburg, H., Schmalzing, G., Deitmer, J. W., and Lohr, C. (2010). Ectopic vesicular neurotransmitter release along sensory axons mediates neurovascular coupling via glial calcium signaling. Proc. Natl. Acad. Sci. U.S.A. 107, 15258-15263. doi: 10.1073/pnas.1003501107 
Tobin, V., Leng, G., and Ludwig, M. (2012). The involvement of actin, calcium channels and exocytosis proteins in somato-dendritic oxytocin and vasopressin release. Front. Physiol. 3:261. doi: 10.3389/fphys.2012.00261

Tobin, V. A., Douglas, A. J., Leng, G., and Ludwig, M. (2011). The involvement of voltage-operated calcium channels in somato-dendritic oxytocin release. PLoS ONE 6:e25366. doi: 10.1371/journal.pone.0025366

Tomioka, K., Uryu, O., Kamae, Y., Umezaki, Y., and Yoshii, T. (2012). Peripheral circadian rhythms and their regulatory mechanism in insects and some other arthropods: a review. J. Comp. Physiol. B, Biochem. Syst. Environ. Physiol. 182, 729-740. doi: 10.1007/s00360-012-0651-1

Trueta, C., and De-Miguel, F. F. (2012). Extrasynaptic exocytosis and its mechanisms: a source of molecules mediating volume transmission in the nervous system. Front. Physiol. 3:319. doi: 10.3389/fphys.2012.00319

Trueta, C., Kuffler, D. P., and De-Miguel, F. F. (2012). Cycling of dense core vesicles involved in somatic exocytosis of serotonin by leech neurons. Front. Physiol. 3:175. doi: 10.3389/fphys.2012.00175

Trueta, C., Méndez, B., and De-Miguel, F. F. (2003). Somatic exocytosis of serotonin mediated by L-type calcium channels in cultured leech neurones. J. Physiol. 547, 405-416. doi: 10.1113/jphysiol.2002.030684

Trueta, C., Sánchez-Armass, S., Morales, M. A., and De-Miguel, F. F. (2004). Calcium-induced calcium release contributes to somatic secretion of serotonin in leech Retzius neurons. J. Neurobiol. 61, 309-316. doi: 10.1002/neu.20055

Trulson, M. E., and Frederickson, C. J. (1987). A comparison of the electrophysiological and pharmacological properties of serotonin-containing neurons in the nucleus raphe dorsalis, raphe medianus and raphe pallidus recorded from mouse brain slices in vitro: role of autoreceptors. Brain Res. Bull. 18, 179-190. doi: 10.1016/0361-9230(87)90189-4

Tsien, R. W., Lipscombe, D., Madison, D. V., Bley, K. R., and Fox, A. P. (1988). Multiple types of neuronal calcium channels and their selective modulation. Trends Neurosci. 11, 431-438. doi: 10.1016/0166-2236(88)90194-4

Van Bockstaele, E. J., and Pickel, V. M. (1993). Ultrastructure of serotoninimmunoreactive terminals in the core and shell of the rat nucleus accumbens: cellular substrates for interactions with catecholamine afferents. J. Comp. Neurol. 334, 603-617. doi: 10.1002/cne.903340408
Visscher, K., Schnitzer, M. J., and Block, S. M. (1999). Single kinesin molecules studied with a molecular force clamp. Nature 400, 184-189. doi: 10.1038/22146

Willard, A. L. (1981). Effects of serotonin on the generation of the motor program for swimming by the medicinal leech. J. Neurosci. 1, 936-944.

Wintermantel, T. M., Campbell, R. E., Porteous, R., Bock, D., Gröne, H.-J., Todman, M. G., et al. (2006). Definition of estrogen receptor pathway critical for estrogen positive feedback to gonadotropin-releasing hormone neurons and fertility. Neuron 52, 271-280. doi: 10.1016/j.neuron.2006.07.023

Xiong, W., and Ferrell, J. E. (2003). A positive-feedback-based bistable "memory module" that governs a cell fate decision. Nature 426, 460-465. doi: 10.1038 /nature02089

Yoo, S. H. (2010). Secretory granules in inositol 1,4,5-trisphosphate-dependent $\mathrm{Ca} 2+$ signaling in the cytoplasm of neuroendocrine cells. FASEB J. 24, 653-664. doi: 10.1096/fj.09-132456

Zhang, X., Chen, Y., Wang, C., and Huang, L.-Y. M. (2007). Neuronal somatic ATP release triggers neuron-satellite glial cell communication in dorsal root ganglia. Proc. Natl. Acad.Sci. U.S.A. 104, 9864-9869. doi: 10.1073/pnas.0611048104

Conflict of Interest Statement: The authors declare that the research was conducted in the absence of any commercial or financial relationships that could be construed as a potential conflict of interest.

Received: 21 March 2014; accepted: 02 June 2014; published online: 27 June 2014. Citation: Leon-Pinzon C, Cercós MG, Noguez P, Trueta C and De-Miguel FF (2014) Exocytosis of serotonin from the neuronal soma is sustained by a serotonin and calcium-dependent feedback loop. Front. Cell. Neurosci. 8:169. doi: 10.3389/fncel. 2014.00169

This article was submitted to the journal Frontiers in Cellular Neuroscience.

Copyright (c) 2014 Leon-Pinzon, Cercós, Noguez, Trueta and De-Miguel. This is an open-access article distributed under the terms of the Creative Commons Attribution License (CC BY). The use, distribution or reproduction in other forums is permitted, provided the original author(s) or licensor are credited and that the original publication in this journal is cited, in accordance with accepted academic practice. No use, distribution or reproduction is permitted which does not comply with these terms. 